\title{
Rab10 regulates the sorting of internalised TrkB to retrograde axonal transport
}

Authors: Oscar M. Lazo ${ }^{1,2}$ and Giampietro Schiavo ${ }^{1,2} *$

Affiliations:

${ }^{1}$ Department of Neuromuscular Diseases, UCL Queen Square Institute of Neurology, University College London, London WC1N 3BG, UK

${ }^{2}$ UK Dementia Research Institute at UCL, London WC1E 6BT, UK

* To whom correspondence should be addressed: Giampietro Schiavo (giampietro.schiavo@ucl.ac.uk)

Word count main text: 4015

Figures: 6

References: 64

Supplementary tables: 2

Key words: Brain-derived neurotrophic factor, signalling endosome, small GTPases 
bioRxiv preprint doi: https://doi.org/10.1101/2021.04.07.438771; this version posted April 7, 2021. The copyright holder for this preprint (which was not certified by peer review) is the author/funder, who has granted bioRxiv a license to display the preprint in perpetuity. It is made available under aCC-BY-ND 4.0 International license.

OM Lazo and G Schiavo, 2021 - pre-print version to be peer reviewed

\section{Abstract}

The extreme, complex morphology of neurons provides an unrivalled model to study the coordination between local signalling and long-range cell responses. A cogent example is provided by the binding of brainderived neurotrophic factor (BDNF) to its receptor TrkB, which triggers signalling cascades at axon terminals that result in responses at the level of the cell body, including modulation of gene expression. Retrograde propagation of these critical signals relies on the sorting of activated TrkB receptors to retrograde axonal transport organelles termed signalling endosomes. In this work, we show that the small GTPase Rab10 is critical for the sorting of activated TrkB receptors to axonal retrograde carriers and the propagation of neurotrophin signalling from the axon terminal to the soma. Moreover, our data indicate that Rab10 defines a novel class of axonal organelles that are mobilised towards the axon terminal upon BDNF stimulation, thus enabling the axon to dynamically adjust the retrograde signalling flow to changes in BDNF availability at the synapse.

\section{Introduction}

Communication between cells depends on their ability to respond as integrated units to spatial and temporal signalling patterns. The complex morphology of neurons provides an unrivalled model to study how sorting and trafficking of signalling complexes coordinate local signalling at the axon terminal and the propagation of messages to the cell body. A clear example is provided by neurotrophic factors secreted by target tissues and sensed by axon terminals, where, among other functions, they regulate local cytoskeletal dynamics to promote or cease axon elongation, induce branching, as well as maturation and plasticity of synapses ${ }^{1-3}$. In parallel, a population of activated receptors are internalised and targeted to the retrograde axonal transport pathway within signalling endosomes ${ }^{4,5}$, which propagate neurotrophic signalling towards the cell body, regulating gene expression, dendritic branching, and the equilibrium between survival and apoptosis ${ }^{6-9}$. How local and central responses are coordinated across the massive distance from axon terminals to the soma is a crucial and still unanswered question for neuronal cell biology.

Brain-derived neurotrophic factor (BDNF), a member of the neurotrophin family, is widely expressed in the central nervous system, together with its receptor tropomyosin-related kinase B (TrkB). By activating diverse signalling cascades, comprising the phosphoinositide 3-kinase (PI3K)-Akt pathway, mitogen-activated protein kinases (MAPKs) and phospholipase C-gamma (PLC $),$ BDNF and TrkB play a critical role in the formation, maintenance and plasticity of neuronal circuits ${ }^{10,11}$. Binding of BDNF at synaptic sites leads to endocytosis of TrkB and accumulation of the activated ligand-receptor complex in early endosomes at axon terminals ${ }^{12}$. Whilst part of the internalised TrkB receptors recycle back to the plasma membrane, a pool of receptors is sorted to signalling endosomes and engage with the cytoplasmic dynein motor, which mediates the transport of these organelles to the soma ${ }^{1,9,13}$. Several lines of evidence indicate that this compartment is generated from early endosomes that then mature into a more specialised organelle that escape acidification and lysosomal degradation ${ }^{5}$. Sorting of TrkB receptors from early to signalling endosomes constitutes the critical regulatory node controlling the intensity of the retrogradely-propagated signal; however, to date no clear mechanism coordinating this sorting process has been proposed. 
bioRxiv preprint doi: https://doi.org/10.1101/2021.04.07.438771; this version posted April 7, 2021. The copyright holder for this preprint (which was not certified by peer review) is the author/funder, who has granted bioRxiv a license to display the preprint in perpetuity. It is made available under aCC-BY-ND 4.0 International license.

OM Lazo and G Schiavo, 2021 - pre-print version to be peer reviewed

The Rab family of monomeric GTPases plays a central role regulating post-endocytic trafficking of TrkB. Whilst early endosome formation is regulated by Rab5, maturation and processive transport of signalling endosomes in different neuronal models are controlled by Rab7 ${ }^{12,14-16}$. However, it is currently unclear whether or not Rab7 is the only member of the Rab family controlling the latter process. Because axonal retrograde signalling endosomes appear to be a diverse group of organelles ${ }^{5}$, we hypothesised that other members of the Rab family also contribute to the segregation of TrkB and sorting to retrograde axonal carriers.

In this work, we specifically focused on Rab10, since it has been shown that Rab10-positive organelles are transported both anterogradely and retrogradely along the axon in hippocampal neurons ${ }^{17}$. Previous work from our laboratory using an affinity purification approach to isolate neurotrophin signalling endosomes from mouse embryonic stem cell-derived motor neurons found that Rab10 was significantly enriched in this axonal compartment, together with Rab5 and Rab7 ${ }^{18}$. By manipulating Rab10 expression and activity in hippocampal neurons, as well as analysing the axonal dynamics of Rab10 organelles, we have explored its ability to regulate the sorting of TrkB to the retrograde axonal transport pathway and respond to increasing concentrations of BDNF, adjusting retrograde signalling on demand.

\section{Results}

\section{Rab10 is required for retrograde TrkB trafficking and signalling}

To study axonal TrkB dynamics, we cultured hippocampal neurons in microfluidic chambers, which allow cellular and fluidic compartmentalisation of axon terminals. After 7 days in vitro, neurons plated in one of the compartments (designated as 'somatic') displayed axons reaching the axonal compartment (Figure 1a). Maintaining a higher volume of media in the somatic compartment allows a micro-flow along the grooves, keeping any substance added to the axonal compartment confined to this area. Using this experimental set up, we incubated axon terminals with an antibody against the extracellular domain of TrkB and induced its endocytosis by adding $20 \mathrm{ng} / \mathrm{mL}$ BDNF. After 2.5 hours, we were able to detect the axonal TrkB in the cell body of neurons stimulated with BDNF, but not in neurons depleted of BDNF by addition of an anti-BDNF blocking antibody (Figure 1 b), confirming the reliability of our retrograde accumulation assay.

The same experimental design was applied to neurons transduced with a doxycycline-inducible lentivirus encoding shRNA targeting Rab10. Neurons treated with the shRNA for 18-22 hours showed lower levels of Rab10 (Figure 1c, grey) and significantly reduced retrograde accumulation of TrkB when compared with neurons expressing control lentivirus (Figure 1c-d). Since expression of Rab10 is variable among neurons, we tested the correlation between the abundance of endogenous Rab10 with the levels of retrograde accumulation of TrkB (Figure 1e). We found that, even though there was a large overlap, control and knockeddown neurons clustered as expected. Moreover, when we take both populations together, we found a significant correlation between Rab10 expression and TrkB accumulation, strongly suggesting that Rab10 plays a role in retrograde axonal transport of internalised TrkB.

To confirm the functional consequences of this decrease on the retrograde transport of TrkB, we treated neurons in the axonal compartment with BDNF and analysed the levels of phosphorylated cAMP response element binding protein ( $p C R E B$ ) in the nucleus. $P C R E B$ is a well-established proxy for neurotrophic signalling in neurons and has been shown to be critical for global neuronal responses to neurotrophins, such as BDNFinduced dendritic branching ${ }^{19}$. Neurons treated with a shRNA directed against Rab10 showed a significant decrease in nuclear pCREB (Figure $1 \mathrm{f}$-g), which was completely rescued by treatment with a lentivirus encoding shRNA-resistant Rab10, further confirming the specificity of this effect. 
bioRxiv preprint doi: https://doi.org/10.1101/2021.04.07.438771; this version posted April 7, 2021. The copyright holder for this preprint (which was not certified by peer review) is the author/funder, who has granted bioRxiv a license to display the preprint in perpetuity. It is made available under aCC-BY-ND 4.0 International license.

OM Lazo and G Schiavo, 2021 - pre-print version to be peer reviewed

\section{Rab10 associates transiently to TrkB-containing retrograde carriers}

Given its critical role regulating retrograde accumulation of TrkB, we investigated whether Rab10 was present in retrograde signalling endosomes. As stated before, signalling endosomes are likely to be a heterogeneous collection of functionally-related organelles with diverse molecular composition ${ }^{5}$. Most of theses axonal carriers are positive for Rab7 ${ }^{12}$, which enables the recruitment of the dynein motor complex and their processive retrograde transport along microtubules ${ }^{9,13}$. Endogenous Rab10 (orange) and Rab7 (green) were detected with specific antibodies and imaged by confocal microscopy (Figure 2a). Co-localisation was evaluated using Manders index and significance determined using confined-displacement algorithm (CDA) ${ }^{20}$. Rab10 and Rab7 were found to exhibit very low co-localisation levels (Figure 2a, yellow arrowheads), both in neurons stimulated with BDNF ( $20 \mathrm{ng} / \mathrm{mL}$ for $30 \mathrm{~min}$ ), as well as in neurons depleted of BDNF by treatment a blocking antibody (Figure 2b). Super-resolution radial fluctuations (SRRF) microscopy was used to examine the distribution of Rab10, Rab7 and Rab5 along the axon of neurons stimulated with BDNF as above. Consistently, we found that Rab10 and Rab7 showed a very low degree of overlap (see yellow regions in Figure 2c and superposition of intensity peaks in $2 \mathrm{~d}$ ). On the other hand, super resolution microscopy showed few organelles where Rab10 and Rab5 partially co-localise (pink regions, Figure 2c-d), suggesting that Rab5-positive retrograde carriers ${ }^{21}$ or stationary early endosomes could contain Rab10.

To identify retrograde signalling endosomes containing TrkB, we took advantage of the property of the nontoxic carboxy-terminal domain of the heavy chain of tetanus neurotoxin $\left(\mathrm{H}_{\mathrm{C}} \mathrm{T}\right)$ of being transported almost exclusively in retrograde axonal organelles in neurons ${ }^{12}$. We co-internalised $\mathrm{H}_{\mathrm{C}} \mathrm{T}$-AlexaFluor647 and mouse anti-Flag antibodies in neurons transfected with a TrkB-Flag construct, and stimulated them with BDNF. Double-positive $\mathrm{TrkB} / \mathrm{H}_{\mathrm{C}} \mathrm{T}$ puncta in the axon were considered retrograde signalling endosomes, and we analysed the proportion of them co-localising with Rab10. Figure 2e represents the relative area of $T r k B / H_{C} T$ and the triple positive area of $\mathrm{TrkB} / \mathrm{H}_{\mathrm{C}} \mathrm{T} / \mathrm{Rab} 10$ across three different time points (30, 60 and 90 minutes) postendocytosis. Whereas the amount of TrkB in retrograde carriers increases with time (cyan) as expected, the proportion of TrkB present in Rab10 organelles remains low and does not increase any further after 60 minutes of incubation (white). These results suggest that TrkB localises transiently on Rab10-positive organelles en route to its delivery to axonal retrograde carriers. This observation is supported by super-resolution images (Figure 2f), showing an increase of $\mathrm{TrkB} / \mathrm{H}_{\mathrm{C}} \mathrm{T}$ double-positive puncta (cyan arrowheads), but very few $\mathrm{TrkB} / \mathrm{H}_{\mathrm{C}} \mathrm{T} /$ Rab10 triple-positive puncta (white empty triangles) at 60 and 90 minutes.

\section{Overexpressed Rab10 is co-transported with retrograde TrkB}

The data presented so far support a model in which Rab10 is critical for retrograde transport of TrkB, but does not specifically define a stable population of retrograde carriers. Rather, the evidence shown in Figure 2e-f suggests that TrkB is transiently associated to Rab10-positive organelles, opening the possibility that Rab10 participates in the sorting of internalised receptors to the retrograde axonal transport compartment. Therefore, we decided to overexpress Rab10-EGFP, since it is well documented that overexpression of Rab GTPases promotes their activity due to increased concentration in the membrane ${ }^{22}$. We expected that an increase in the abundance and/or activity of Rab10 stabilises its presence in TrkB retrograde carriers for enough time to give us the chance to visualise this potential interaction in live neurons.

To test this hypothesis, neurons were co-transfected with Rab10-EGFP and TrkB-Flag and, after 1 hour of starvation in non-supplemented Neurobasal, we internalised AlexaFluor647-labelled anti-Flag antibodies in the presence of BDNF for 45 min (Figure 3a). Live-cell confocal imaging of axon segments was performed at least $200 \mu \mathrm{m}$ from the cell body. Representative frames of the time-lapse movie are shown in Figure 3b, where 
bioRxiv preprint doi: https://doi.org/10.1101/2021.04.07.438771; this version posted April 7, 2021. The copyright holder for this preprint (which was not certified by peer review) is the author/funder, who has granted bioRxiv a license to display the preprint in perpetuity. It is made available under aCC-BY-ND 4.0 International license.

OM Lazo and G Schiavo, 2021 - pre-print version to be peer reviewed

retrograde co-transport of TrkB and Rab10-EGFP is indicated with yellow arrowheads. Kymographs (Figure 3c) were generated for Rab10-EGFP (orange) and TrkB-Flag (green). Tracks are shown in the bottom panel, with examples of co-transport as yellow lines. Quantification of five independent experiments (Figure 3d) confirmed that approximately $60 \%$ of retrograde TrkB carriers are positive for Rab10. Interestingly, no anterograde TrkB/Rab10 double-positives compartments were observed, suggesting that TrkB is present in organelles with a strong retrograde bias.

To extend this analysis to the other neurotrophin receptor responding to BDNF, a similar experiment was done by monitoring the internalisation of endogenous $\mathrm{p} 75^{\mathrm{NTR}}$ in neurons transfected with Rab10-EGFP. After depletion of trophic factors, p75 NTR uptake was visualised by incubating neurons for 45 min with an AlexaFluor647-labelled antibody against the extracellular domain of $\mathrm{p} 75^{\mathrm{NTR}}$ in the presence of BDNF (Figure 3e). Live-cell imaging of axon segments was done under conditions identical to those for TrkB. Representative frames and kymographs of Rab10-EGFP (orange) and internalised p75 NTR (green) are shown in the Figure $3 \mathrm{f}$-g. Kymograph traces show that $\mathrm{p} 75^{\mathrm{NTR}}$ receptor can be found in both retrograde and anterograde Rab10 organelles. On average, $29.6 \%$ of anterograde and $15.5 \%$ of retrograde $\mathrm{p} 75^{\mathrm{NTR}}$ carriers were found positive for Rab10 across five independent experiments (Figure $3 \mathrm{~h}$ ).

\section{Increasing BDNF favours anterograde trafficking of Rab10 organelles}

In agreement with the bidirectional transport observed for $p 75^{\mathrm{NTR}}$ organelles (Figure $3 \mathrm{~h}$ ), previous work suggested that Rab10-positive compartments are transported along the axon in both directions ${ }^{17}$. In light of these results, we hypothesised that the dynamics of Rab10 organelles may respond to BDNF signalling to regulate the sorting of TrkB to retrograde carriers. We therefore examined the axonal transport of Rab10positive organelles in hippocampal neurons under two opposite conditions: depletion of BDNF using an antiBDNF blocking antibody, followed by stimulation with $50 \mathrm{ng} / \mathrm{mL}$ BDNF.

Figure 4a shows representative frames of a Rab10-EGFP organelle moving in the retrograde direction along the axon (white arrows) in the absence of BDNF. Five-minutes segments of video microscopy have been integrated in each kymograph (Figure $4 b$ ) at different time points of BDNF stimulation: before BDNF (top), immediately after BDNF addition (centre) and after 10 min of BDNF incubation (bottom). Traces have been colour-coded as retrograde (cyan), anterograde (pink) or stationary/bidirectional (yellow) to reveal changes in the direction bias of the Rab10 organelles in the same axon, before and after the addition of BDNF. Quantification of five independent experiments shows that BDNF-depleted axons exhibit a bias towards retrograde Rab10 transport, which significantly switches to anterograde after 10 min of stimulation with BDNF.

These surprising results reveals a novel mechanism ensuring a tight balance between retrograde and anterograde transport of Rab10 organelles, which is fine-tuned by extracellular BDNF levels. As a consequence, any local increase in BDNF release from post-synaptic compartments will escalate the abundance of Rab10 organelles in the immediate vicinity, either by mobilising or retaining them at the distal axonal sites.

\section{Rab10 regulates the sorting of TrkB in early endosomes, with no effect on recycling}

After endocytosis, TrkB accumulates in early endosomes, from which it is sorted either to the recycling route or to endosomal organelles with signalling capabilities ${ }^{9,12}$. Rab10, on the other hand, has been shown to regulate trafficking across early endosomes, the formation of specialised tubular endosomes, recycling of cargoes back to the plasma membrane, as well as targeting of plasmalemmal precursor vesicles (PPVs), among other functions ${ }^{17,23-26}$. To understand the mechanism linking Rab10-positive compartments with the 
bioRxiv preprint doi: https://doi.org/10.1101/2021.04.07.438771; this version posted April 7, 2021. The copyright holder for this preprint (which was not certified by peer review) is the author/funder, who has granted bioRxiv a license to display the preprint in perpetuity. It is made available under aCC-BY-ND 4.0 International license.

OM Lazo and G Schiavo, 2021 - pre-print version to be peer reviewed

retrograde axonal transport of TrkB in signalling endosomes, we designed experiments to discern between a potential role of Rab10 on recycling of internalised TrkB back to the plasma membrane, and sorting of TrkB out to the early endosome into retrograde transport carriers (Figure 5a).

To assess the contribution of Rab10 to the recycling of TrkB in the axon, hippocampal neurons were transfected with EGFP or a dominant negative mutant of Rab10 (Rab10 ${ }^{\mathrm{T} 23 \mathrm{~N}}$; referred as Rab10DN) and TrkBFlag. Endocytosis of anti-Flag M1 antibodies was allowed for 30 minutes in the presence of BDNF, and then the remaining antibody still bound to the neuronal surface was removed using EDTA, which dissociates this antibody from the bound Flag peptide ${ }^{27}$. Recycling receptors were then chased using AlexaFluor647conjugated secondary antibodies. After fixation, internalised TrkB-Flag was revealed using AlexaFluor555conjugated secondary antibodies (Figure $5 \mathrm{~b}$ ). Comparison between recycling ratio (recycled/internalised) of EGFP- and Rab10DN-expressing neurons shows no significant differences (Figure 5c).

In contrast, if the sorting of TrkB to signalling endosomes was regulated by Rab10, expression of Rab10DN would result in the trapping of TrkB in early endosomes, driving an increase of co-localisation between internalised TrkB and Rab5. Therefore, we incubated neurons transfected with TrkB-Flag and either EGFP or Rab10DN, with anti-Flag antibodies for $30 \mathrm{~min}$ in the presence of BDNF, and then analysed TrkB/Rab5 colocalisation using Manders index and CDA (Figure 5d-e). Rab10DN caused a statistically significant increase of internalised TrkB in Rab5-positive domains from $13.2 \% \pm 1.7$ to $22.2 \% \pm 2.8$, and an increase in the reliability of the co-localisation measurements (CDA $p<0.05$ ) (Figure $5 e$ ). These results indicate that the probability of finding axonal TrkB in a Rab5-positive early endosome increases in neurons expressing Rab10DN, thus indicating that Rab10 modulates the sorting of activated TrkB receptors from axonal early endosomes to retrograde transport organelles.

\section{Discussion}

Our results unravel a novel role for Rab10 in regulating the sorting of internalised TrkB receptors to the retrograde axonal transport pathway. This function appears to be necessary not only for efficient trafficking of TrkB from axons to soma, but also for the propagation of neurotrophic signalling to the nucleus, as shown by the decrease of BDNF-induced CREB activation upon Rab10 knock down (Figure 1). CREB is a transcription factor well known for supporting survival, differentiation and morphology of neurons, which is activated by phosphorylation downstream to the Akt and MAPK branches of neurotrophic signalling ${ }^{28}$. Some of the better characterised early response genes to neurotrophic factors (e.g., Egr1, Egr2, Arc and cFos) are transcriptional targets of CREB, which is also required for BDNF-induced dendritic branching 19,29,30. Therefore, CREB phosphorylation is one of the best proxies for global cell responses to neurotrophic signalling. Long-distance activation of CREB has been reported from distal axons and dendrites, and trafficking across endosomal compartments of $\mathrm{pCREB}$ has been shown to play a crucial role in propagating neurotrophin signalling from the periphery to the nucleus ${ }^{8,31,32}$. Interestingly, in our study we observed that expression of functional Rab10 was critical for maintenance and survival of differentiated neurons, since whenever we forced the downregulation of Rab10 or expressed Rab10DN for 48 hours or more, changes in dendritic and axonal arborisation and a decrease in cell viability were observed (not shown). Similar effects have been reported upon the overexpression of dominant-negative mutants of Rab5, the GTPase mediating formation of early endosomes, but not for Rab11, which controls the slow recycling of receptors to the plasma membrane ${ }^{33,34}$, suggesting that the distinct arms of the endosomal network differentially impact on neuronal homeostasis.

In general, small GTPases of the Rab family have been defined by the specificity of the trafficking process they facilitate. Acting as a highly specialised network, they constitute one of the master regulators of membrane trafficking in eukaryotic cells ${ }^{32}$. Rab10 is one of the few exceptions to this rule and during the last 30 years, it 
bioRxiv preprint doi: https://doi.org/10.1101/2021.04.07.438771; this version posted April 7, 2021. The copyright holder for this preprint (which was not certified by peer review) is the author/funder, who has granted bioRxiv a license to display the preprint in perpetuity. It is made available under aCC-BY-ND 4.0 International license.

OM Lazo and G Schiavo, 2021 - pre-print version to be peer reviewed

has been associated to multiple trafficking pathways, including polarised exocytosis from early endosomes, specific exocytic mechanisms in adipocytes and neurons, endoplasmic reticulum dynamics and the formation of tubular endosomes, to cite but a few ${ }^{35}$. This multiplicity of functions is reflected by the diversity of its interactors and effectors, emphasising the importance of the specific context in which Rab10 operates. Here we have confirmed previous findings showing that Rab10-positives organelles are present in the axon of hippocampal neurons and display bi-directional transport ${ }^{17}$. Importantly, in this work, we have demonstrated that the balance between anterograde and retrograde transport is regulated by BDNF stimulation, indicating the ability of Rab10 to specifically respond to extracellular cues in a signalling context. A similar function of Rab10 balancing anterograde and retrograde transport has been shown to be required for correct dendritic patterning in Drosophila ${ }^{36}$.

Although the mechanism by which Rab10-positive organelles switch between retrograde and anterograde transport has not been the focus of this work, two key observations suggest that directionality does not depend on Rab10 active status. First, both anterograde and retrograde organelles have membrane-bound Rab10 (Figure 4), which is generally accepted to be its GTP-bound active form. Accordingly, the Rab10-T23N dominant-negative mutant, which resembles GDP-bound Rab10, displays a diffuse cytoplasmic distribution. Second, we observed that the Rab10-Q68L constitutively-active mutant is transported predominantly in retrograde direction in neurons depleted of BDNF (data not shown). Altogether these observations suggest that the GTP-bound conformation of Rab10 is required to interact with the membrane of axonal organelles, but is not sufficient to determine the direction of transport.

Phosphorylation of Rab10 by the Leucine-rich repeat kinase 2 (LRRK2) has been shown to regulate interaction with JIP3 and JIP4 ${ }^{37}$, which are adaptors for the plus-end-directed microtubule-dependent molecular motor kinesin-1 ${ }^{38,39}$. Interestingly, JIP3 has been shown to mediate TrkB anterograde transport in neurons and, by that mechanism, to enhance BDNF signalling ${ }^{40,41}$. Although the mechanism by which TrkB signalling promotes recruitment and activation of LRRK2 in Rab10-positive organelles is currently only a matter of speculation, one of the most interesting candidates to mediate this process is Vps35, a component of the retromer complex, which has been shown to modulate LRRK2 ${ }^{42}$. Consistent with this view, TrkB binds SorLA, a key factor for retromer assembly ${ }^{43}$. It is therefore possible that the first wave of TrkB-containing signalling endosomes induces the phosphorylation of Rab10 through the Vps35-LRRK2 recruitment, leading to the mobilisation (or retention) of Rab10-positive organelles at the cell periphery. This proposed mechanism could be particularly attractive in the context of certain models of neurodegeneration, given the genetic links between LRRK2 and Parkinson's disease (PD) ${ }^{44,45}$ and the neuroprotective role shown for BDNF in neurons of the substantia nigra in PD models ${ }^{46,47}$.

In addition, activity and phosphorylation of Rab10 could be controlled by canonical TrkB signalling pathways, including PI3K-Akt. In adipocytes and muscle cells, Rab10 is known to regulate the plasma membrane delivery of the glucose transporter GLUT4 in response to insulin, where activation of Akt leads to phosphorylation of the Rab GAP Akt substrate of 160 kDa (AS160). Rab10 associated to GLUT4-containing endosomes is kept inactive by AS160, until Akt signalling releases the brake promoting fusion with the plasma membrane ${ }^{48}$. Interestingly, it has been recently shown that LRRK2 is required for efficient insulin-stimulated translocation of GLUT4, and the effects of LRRK2 depletion can be compensated by increasing Akt signalling ${ }^{49}$. Whether TrkB-PI3K-Akt is able to positively regulate phosphorylation of Rab10 is an interesting possibility we aim to explore in the near future.

Once internalised, axonal TrkB reaches early endosomes, from where it can either recycle back to the plasma membrane, thus fine-tuning the response of the nerve terminal to BDNF (reviewed in ${ }^{50}$ ), or undergo sorting to the retrograde axonal transport route, propagating the neurotrophic signal to the soma ${ }^{9,12,13}$. Given that 
bioRxiv preprint doi: https://doi.org/10.1101/2021.04.07.438771; this version posted April 7, 2021. The copyright holder for this preprint (which was not certified by peer review) is the author/funder, who has granted bioRxiv a license to display the preprint in perpetuity. It is made available under aCC-BY-ND 4.0 International license.

OM Lazo and G Schiavo, 2021 - pre-print version to be peer reviewed

Rab10 downregulation decreased retrograde transport of TrkB and stimulation with BDNF promoted anterograde transport of Rab10, we reasoned that Rab10 delivery to the axon terminal facilitated sorting of TrkB to retrogradely transported compartments. We demonstrated that the expression of Rab10DN increases the amount of internalised TrkB accumulated in early endosomes without significantly affecting recycling (Figure 5), a result that indicates functional Rab10 aids the sorting of TrkB away from early endosomes and to a distinct axonal compartment.

Internalised Rab10 is found in retrograde signalling endosomes positive for TrkB or p75 ${ }^{\text {NTR }}$ (Figure 3). However, when we studied triple co-localisation of internalised $H_{C} T$ and TrkB with endogenous Rab10, we found the absolute amount of retrograde TrkB in Rab10 organelles to remain constantly low, even when the total amount of retrogradely-transported TrkB increases three times from 30 to $90 \mathrm{~min}$ (Figure 2e), suggesting that this interaction is transient. This is in line with previous evidence showing that in MDCK cells, Rab10 mediates transport from early endosomes to a polarised trafficking route ${ }^{23}$. Moreover, in C. elegans, Rab10 is recruited to early endosomes where it downregulates Rab5, helping to select cargoes for delivery to other endosomal compartments, in this case recycling endosomes ${ }^{51}$. Among other functions, Rab10 has been shown to participate in the biogenesis of tubular endosomes in mammalian cells ${ }^{25}$, which together with evidence indicating that Rab10 regulates endosomal phosphatidylinositol-4,5-bisphosphate in C. elegans, suggests that Rab10 modulates the membrane recruitment of factors altering membrane curvature and vesicle budding ${ }^{52}$.

Our data suggests that Rab10 regulates the amount of internalised TrkB that is sorted to retrograde signalling endosomes, depending on the concentration of BDNF at the axon terminal. Since BDNF is known to be released from the post-synaptic membrane depending on neuronal activity ${ }^{53}$, retrograde neurotrophic signalling from the axon terminal is a substantial feedback mechanism regulating growth and survival, and therefore, ensuring that the active circuit is preserved. To keep this feedback signal meaningful, any change in the availability of BDNF at the synapse has to translate into proportional changes in the intensity of the signal perceived at the soma. We propose that Rab10 organelles deliver crucial components of the sorting machinery on demand. At steady state, anterograde and retrograde transport of Rab10 organelles are in equilibrium (Figure 6; low $B D N F)$. Further decrease in BDNF concentration makes retrograde transport of Rab10 compartments predominant, as observed in live-cell imaging experiments performed in neurons treated with anti-BDNF blocking antibodies (Figure 4, no BDNF). In contrast, adding BDNF reverts the directional bias of Rab10 organelles to anterograde (Figure 6; high BDNF), which allows the delivery of appropriate levels of the sorting machinery to the nerve terminal, thus increasing the efficiency of TrkB retrograde transport.

Little is known about the specific sorting machinery required for the biogenesis of signalling endosomes. Endophilins A1 and A3 have been shown to regulate the trafficking of TrkB across early endosomes and mediate survival signalling ${ }^{14,54}$. Interestingly, LRRK2 substrates include endophilin A1 as well as Rab10, opening the possibility of both being found on the same organelle ${ }^{55}$. Further identification of components of the sorting machinery delivered to the axonal terminal by Rab10-positive compartments will be crucial to understand not only how this mechanism allows coordination between local signalling and global neuronal responses, but also how this process may fail in neurodegeneration. In this light, promoting the delivery of Rab10 organelles to nerve terminals may be explored as an innovative therapeutic strategy for diseases in which the endo-lysosomal system is overloaded or dysfunctional, such as Alzheimer's disease ${ }^{56,57}$, or to increase the ability of axons to respond to trophic factors during regeneration.

\section{Methods}

A summary of all the antibodies, plasmids and lentiviral vectors used in this work can be found in the Supplementary Table 1. 
bioRxiv preprint doi: https://doi.org/10.1101/2021.04.07.438771; this version posted April 7, 2021. The copyright holder for this preprint (which was not certified by peer review) is the author/funder, who has granted bioRxiv a license to display the preprint in perpetuity. It is made available under aCC-BY-ND 4.0 International license.

OM Lazo and G Schiavo, 2021 - pre-print version to be peer reviewed

\section{Neuronal cultures}

Embryonic hippocampal neurons from C57BL/6 mice of either sex and embryonic age of 16-17 days where dissected adapting previously described protocols ${ }^{58}$. Dissection was performed in cold Hanks' balanced salt solution (HBSS) and the tissue was collected in cold Hibernate E medium (ThermoFisher, \#A1247601). After incubating for $10 \mathrm{~min}$ in $300 \mu \mathrm{L}$ of Accumax (Innovative Cell Technologies, \#AM105) diluted in HBSS (1:1), tissue was washed in HBSS, resuspended in warm plating medium (Minimum Essential Medium supplemented with $10 \%$ horse serum, $6 \%$ glucose and $2 \mathrm{mM}$ glutamine) and mechanically dissociated by pipetting. 10,00012,000 neurons per $\mathrm{cm}^{2}$ were then seeded on glass coverslips or microfluidic chambers, pre-coated with 1 $\mathrm{mg} / \mathrm{mL}$ poly-L-lysine. Before coating, glass coverslips were treated overnight with NoChromix (Godax Laboratories), washed three times and sterilised in $70 \%$ ethanol. Microfluidic chambers were produced inhouse as previously described ${ }^{59,60}$. Polydimethylsiloxane inserts were fabricated from resin moulds, which are replicas of the master template produced by soft lithography, and then irreversibly bound to glass-bottom dishes (WillCo Wells, \#HBSB-3512) by plasma treatment. Neurons were left in plating medium for $1.5 \mathrm{~h}$ and then shifted to maintenance medium (Neurobasal supplemented with B27, $2 \mathrm{mM}$ glutamine, $6 \%$ glucose and antibiotics). Half of the culture medium was replaced by fresh medium every 3-4 days.

\section{Immunofluorescence.}

Neurons were washed in phosphate buffer saline (PBS) and fixed for $15 \mathrm{~min}$ in 3\% PFA and 4\% sucrose dissolved in PBS. Next, cells were incubated in $0.15 \mathrm{M}$ glycine dissolved in PBS for 10 minutes and then blocked and permeabilised simultaneously by incubation for $1 \mathrm{~h}$ in $5 \%$ BSA and $0.1 \%$ saponin in PBS. Samples were incubated at $4^{\circ} \mathrm{C}$ overnight with primary antibodies diluted in $5 \% \mathrm{BSA}, 0.05 \%$ saponin, $0.1 \mathrm{mM} \mathrm{CaCl}_{2}$ and 0.1 $\mathrm{mM} \mathrm{MgCl} 2$ dissolved in PBS at the following concentrations: 1:50 goat anti-Rab10 (Santa Cruz Biotechnologies, cat no. sc-6564, RRID:AB_2237844); 1:200 mouse anti-Rab10 (Abcam, cat no. ab104859, RRID:AB_10711207); 1:200 rabbit anti-Rab10 (Cell Signalling Technology, cat no. 8127, RRID:AB_10828219); 1:300 chicken anti-ßIII tubulin (Synaptic Systems, cat no. 302 306, AB_2620048); 1:250 rabbit anti-phosphorylated CREB S133 (Abcam, cat no. ab32096, RRID:AB_731734); 1:200 mouse anti-Rab7 (Abcam, cat no. ab50533, RRID:AB_882241); and 1:200 rabbit anti-Rab5 (Abcam, cat no. ab13253, RRID:AB_299796). Then, neurons were washed three times with PBS and incubated for $90 \mathrm{~min}$ with AlexaFluor-conjugated secondary antibodies 1:400 (ThermoFisher) in 5\% BSA, $0.05 \%$ saponin, $0.1 \mathrm{mM} \mathrm{CaCl}_{2}$ and $0.1 \mathrm{mM} \mathrm{MgCl}_{2}$ dissolved in PBS. Nuclear staining 4',6-diamidino-2-phenylindole (DAPI) was added with the secondary antibodies when appropriate. Finally, coverslips were washed in PBS and mounted with Mowiol.

\section{Transfection and plasmids}

Hippocampal neurons were transfected at 7 days in vitro (DIV) using Lipofectamine 2000 (ThermoFisher). Experiments were carried out after 20-24 h. The pEGFP-C1 plasmid is from Clontech (Addgene plasmid \# 13031, RRID:Addgene_13031), the plasmids for Rab10 WT EGFP (RRID:Addgene_49472) and Rab10 T23N EGFP (RRID:Addgene_49545) were a gift from Marci Scidmore ${ }^{61}$, TrkB-FLAG plasmid was a gift from Francis Lee ${ }^{27}$.

\section{Retrograde accumulation and signalling assays}

After 7 DIV, microfluidic chambers with overt axon crossing were selected. Rab10 was knocked down by transducing neurons with an inducible shRNA Rab10 lentivirus (pTightPuro-shRNA Rab10) and its doxycyclinedependent regulator TET-ON Advance. The day before the experiment, doxycycline $1 \mu \mathrm{g} / \mathrm{mL}$ was added to the cell bodies and 18-22 $\mathrm{h}$ later, the media was replaced with Neurobasal in somatic and axonal compartments to deplete cells from endogenous growth factors for $1 \mathrm{~h}$. For analysing the retrograde accumulation of TrkB, we added polyclonal antibodies against the extracellular domain of TrkB (1:50 rabbit anti-TrkB, Millipore, cat no. AB9872, RRID:AB_2236301) together with $20 \mathrm{ng} / \mathrm{mL}$ BDNF for $2.5 \mathrm{~h}$. After PFA fixation, the transport of internalized antibodies was revealed by incubating the somatic compartment with fluorescently-labelled 
bioRxiv preprint doi: https://doi.org/10.1101/2021.04.07.438771; this version posted April 7, 2021. The copyright holder for this preprint (which was not certified by peer review) is the author/funder, who has granted bioRxiv a license to display the preprint in perpetuity. It is made available under aCC-BY-ND 4.0 International license.

OM Lazo and G Schiavo, 2021 - pre-print version to be peer reviewed

secondary antibodies. The same protocol was used to study retrograde propagation of neurotrophic signalling; after $1 \mathrm{~h}$ of growth factor-depletion, axons were stimulated with $20 \mathrm{ng} / \mathrm{mL}$ BDNF for $2.5 \mathrm{~h}$ and after fixation, phosphorylation of CREB in the nucleus was analysed by immunofluorescence.

\section{Co-localisation studies}

To analyse the presence of two markers in the same organelle, we used confocal z-stack images (voxel size: $0.197 \times 0.197 \times 0.5 \mu \mathrm{m}$ ) and the confined displacement algorithm to measure Manders' correlation index within axons and determine its statistical significance compared to random images of identical total intensity and shape ${ }^{20}$. To compute random scenarios, seven random radial displacements were taken at a maximum radial distance of 12 pixels (a total of 353 samples), and histograms binning $=16$. CDA was implemented by using the plugin from the GDSC University of Sussex (http://www.sussex.ac.uk/gdsc/intranet/microscopy/UserSupport/AnalysisProtocol/imagej/colocalisation).

All the data points were plotted and the mean and standard error is indicated for each group and compared using Student t-test. Statistical significance of the individual data point is colour coded (see figure legends).

\section{Super-resolution radial fluctuations}

High-fidelity super-resolution information was extracted from time series of 1,000 confocal images per channel by using super-resolution radial fluctuations (SRRF) algorithm ${ }^{62}$. Super-resolution images were then quality-controlled by using Super-Resolution Quantitative Image Rating and Reporting of Error Locations (SQUIRREL) algorithm ${ }^{63}$. Implementation of the algorithms was done in FIJI by using the open-source plugin NanoJ-core (https://henriqueslab.github.io/resources/NanoJ).

\section{Immunoendocytosis}

Hippocampal neurons transfected with TrkB-Flag were kept in Neurobasal media for $1 \mathrm{~h}$ and then incubated on ice with 1:50 mouse anti-Flag antibody (Sigma-Aldrich Cat no. F3040, RRID:AB_439712). In selected

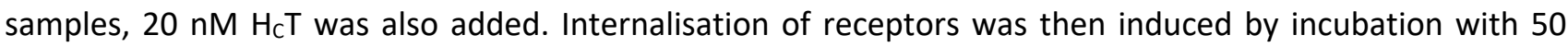
$\mathrm{ng} / \mathrm{mL}$ BDNF for $30 \mathrm{~min}$ at $37^{\circ} \mathrm{C}$. Antibodies bound to receptors still at the cell surface were dissociated by washing twice for $1 \mathrm{~min}$ in PBS supplemented with $1 \mathrm{mM}$ EDTA. In experiments to measure recycling of internalised receptors, neurons were further stimulated with BDNF for other $60 \mathrm{~min}$ in the presence of an AlexaFluor647-conjugated anti-mouse secondary antibody, fixed, permeabilised and incubated with an AlexaFluor555-conjugated anti-mouse secondary antibody to detect total internalised receptor.

\section{Axonal transport}

Axonal transport of overexpressed fluorescent proteins and internalised fluorescent antibodies was analysed from confocal time series of $1 \mathrm{frame} / \mathrm{s}$ and a pixel size of $\sim 0.1 \times 0.1 \mu \mathrm{m}^{2}$, captured during 5 min intervals at different time points by using a Zeiss LSM 780 NLO multiphoton confocal microscope with an oil immersion $63 \times$ objective and equipped with an environmental chamber (Zeiss XL multi S1 DARK LS set at $37^{\circ} \mathrm{C}$ and environmental $\mathrm{CO}_{2}$ ). For these experiments, neurons were cultured on $25 \mathrm{~mm}$ coverslips kept in Neurobasal for $1 \mathrm{~h}$ prior to cell imaging and mounted inside Attofluor chambers (Thermo-Fisher Scientific, Cat no. A7816) with BrightCell NEUMO photostable media (Sigma-Aldrich, Cat no. SCM145). Speed, pausing and direction of labelled organelles were analysed from kymographs by using Kymoanalyzer set of macros from Encalada lab (https://www.encalada.scripps.edu/kymoanalyzer) ${ }^{64}$.

\section{Statistical Analysis}

Samples collected in independent experiments were tested for normality and homoscedasticity to apply the appropriate corrections to the statistical tests. Each specific test, its degrees of freedom and level of significance are indicated in the respective figure legend. All the details are summarised in the statistical annex (Supplementary Table 2). Plots show mean \pm standard error and exact $p$ values are indicated when relevant. 


\section{Software}

Images were handled, edited and analysed using ImageJ/FIJI (version 2.1.0, 1.53c). Figures were checked with Coblis (https://www.color-blindness.com/coblis-color-blindness-simulator/), using The Colour Blind Simulator algorithms from Matthew Wickline and the Human-Computer Interaction Resource Network. Palettes were adjusted to maximise visibility. The Orange/Green/Purple balanced look-up table was obtained from Christophe Leterrier's GitHub repository (https://github.com/cleterrier/ChrisLUTs). Database files were imported, analysed and sorted as R files using RStudio (version 1.0.44). GraphPad Prism for Mac (version 6.00, GraphPad Software) was used for running statistical analysis and generate the plots included in the figures. Illustrations were created with BioRender (http://www.biorender.com). Updated versions of ImageJ macros and $\mathrm{R}$ scripts used in this article, as well as the specific implementation of Kymoanalyzer used to analyse our datasets, can be found on our GitHub repository (https://github.com/omlazo).

\section{Acknowledgements}

We thank Dr James N Sleigh (UCL Queen Square Institute of Neurology) for critical reading of the manuscript. This work was supported by the MRC Project grant MR/T001976/1 [OL], the Wellcome Trust Senior Investigator Award (107116/Z/15/Z) [GS] and the UK Dementia Research Institute Foundation award UKDRI$1005[\mathrm{GS}]$.

\section{Author's contributions}

OL performed the research and drafted the manuscript, which was revised by GS. OL and GS interpreted the data and approved submission of this work.

\section{Conflict of Interest}

The authors have no competing interest to declare. 
bioRxiv preprint doi: https://doi.org/10.1101/2021.04.07.438771; this version posted April 7, 2021. The copyright holder for this preprint (which was not certified by peer review) is the author/funder, who has granted bioRxiv a license to display the preprint in perpetuity. It is made available under aCC-BY-ND 4.0 International license.

OM Lazo and G Schiavo, 2021 - pre-print version to be peer reviewed

\section{References}

1 Andres-Alonso, M. et al. SIPA1L2 controls trafficking and local signaling of TrkB-containing amphisomes at presynaptic terminals. Nat Commun 10, 5448, doi:10.1038/s41467-019-13224-z (2019).

2 Szobota, S. et al. BDNF, NT-3 and Trk receptor agonist monoclonal antibodies promote neuron survival, neurite extension, and synapse restoration in rat cochlea ex vivo models relevant for hidden hearing loss. PLoS One 14, e0224022, doi:10.1371/journal.pone.0224022 (2019).

3 Woo, D. et al. Locally Activating TrkB Receptor Generates Actin Waves and Specifies Axonal Fate. Cell Chem Biol 26, 1652-1663 e1654, doi:10.1016/j.chembiol.2019.10.006 (2019).

4 Barford, K., Deppmann, C. \& Winckler, B. The neurotrophin receptor signaling endosome: Where trafficking meets signaling. Dev Neurobiol 77, 405-418, doi:10.1002/dneu.22427 (2017).

5 Villarroel-Campos, D., Schiavo, G. \& Lazo, O. M. The many disguises of the signalling endosome. FEBS Lett 592, 3615-3632, doi:10.1002/1873-3468.13235 (2018).

6 Du, J. L. \& Poo, M. M. Rapid BDNF-induced retrograde synaptic modification in a developing retinotectal system. Nature 429, 878-883, doi:10.1038/nature02618 (2004).

7 Pazyra-Murphy, M. F. et al. A retrograde neuronal survival response: target-derived neurotrophins regulate MEF2D and bcl-w. J Neurosci 29, 6700-6709, doi:10.1523/JNEUROSCI.0233-09.2009 (2009). Watson, F. L. et al. Rapid nuclear responses to target-derived neurotrophins require retrograde transport of ligand-receptor complex. J Neurosci 19, 7889-7900 (1999).

9 Zhou, B., Cai, Q., Xie, Y. \& Sheng, Z. H. Snapin recruits dynein to BDNF-TrkB signaling endosomes for retrograde axonal transport and is essential for dendrite growth of cortical neurons. Cell Rep 2, 42-51, doi:10.1016/j.celrep.2012.06.010 (2012).

10 Huang, E. J. \& Reichardt, L. F. Trk receptors: roles in neuronal signal transduction. Annu Rev Biochem 72, 609-642, doi:10.1146/annurev.biochem.72.121801.161629 (2003).

11 Minichiello, L. TrkB signalling pathways in LTP and learning. Nat Rev Neurosci 10, 850-860, doi:10.1038/nrn2738 (2009).

12 Deinhardt, K. et al. Rab5 and Rab7 control endocytic sorting along the axonal retrograde transport pathway. Neuron 52, 293-305, doi:10.1016/j.neuron.2006.08.018 (2006).

$13 \mathrm{Ha}$, J. et al. A neuron-specific cytoplasmic dynein isoform preferentially transports TrkB signaling endosomes. J Cell Biol 181, 1027-1039, doi:10.1083/jcb.200803150 (2008).

14 Burk, K. et al. EndophilinAs regulate endosomal sorting of BDNF-TrkB to mediate survival signaling in hippocampal neurons. Sci Rep 7, 2149, doi:10.1038/s41598-017-02202-4 (2017).

15 Kucharava, K. et al. Sodium-hydrogen exchanger 6 (NHE6) deficiency leads to hearing loss, via reduced endosomal signalling through the BDNF/Trk pathway. Sci Rep 10, 3609, doi:10.1038/s41598-02060262-5 (2020).

16 Bucci, C., Alifano, P. \& Cogli, L. The role of Rab proteins in neuronal cells and in the trafficking of neurotrophin receptors. Membranes (Basel) 4, 642-677, doi:10.3390/membranes4040642 (2014).

17 Deng, C. Y. et al. JIP1 mediates anterograde transport of Rab10 cargos during neuronal polarization. J Neurosci 34, 1710-1723, doi:10.1523/JNEUROSCI.4496-13.2014 (2014).

18 Debaisieux, S., Encheva, V., Chakravarty, P., Snijders, A. P. \& Schiavo, G. Analysis of Signaling Endosome Composition and Dynamics Using SILAC in Embryonic Stem Cell-Derived Neurons. Mol Cell Proteomics 15, 542-557, doi:10.1074/mcp.M115.051649 (2016).

19 Gonzalez-Gutierrez, A., Lazo, O. M. \& Bronfman, F. C. The Rab5-Rab11 Endosomal Pathway is Required for BDNF-Induced CREB Transcriptional Regulation in Hippocampal Neurons. J Neurosci 40, 8042-8054, doi:10.1523/JNEUROSCI.2063-19.2020 (2020). 
bioRxiv preprint doi: https://doi.org/10.1101/2021.04.07.438771; this version posted April 7, 2021. The copyright holder for this preprint (which was not certified by peer review) is the author/funder, who has granted bioRxiv a license to display the preprint in perpetuity. It is made available under aCC-BY-ND 4.0 International license.

OM Lazo and G Schiavo, 2021 - pre-print version to be peer reviewed

20

21

22

23

24

25

26

27

28

29

30

31

Ramirez, O., Garcia, A., Rojas, R., Couve, A. \& Hartel, S. Confined displacement algorithm determines true and random colocalization in fluorescence microscopy. J Microsc 239, 173-183, doi:10.1111/j.1365-2818.2010.03369.x (2010).

1 Goto-Silva, L. et al. Retrograde transport of Akt by a neuronal Rab5-APPL1 endosome. Sci Rep 9, 2433, doi:10.1038/s41598-019-38637-0 (2019).

2 Zhen, Y. \& Stenmark, H. Cellular functions of Rab GTPases at a glance. J Cell Sci 128, 3171-3176, doi:10.1242/jcs.166074 (2015).

3 Babbey, C. M. et al. Rab10 regulates membrane transport through early endosomes of polarized Madin-Darby canine kidney cells. Mol Biol Cell 17, 3156-3175, doi:10.1091/mbc.e05-08-0799 (2006).

4 Brewer, P. D., Habtemichael, E. N., Romenskaia, I., Mastick, C. C. \& Coster, A. C. Glut4 Is Sorted from a Rab10 GTPase-independent Constitutive Recycling Pathway into a Highly Insulin-responsive Rab10 GTPase-dependent Sequestration Pathway after Adipocyte Differentiation. J Biol Chem 291, 773-789, doi:10.1074/jbc.M115.694919 (2016).

5 Etoh, K. \& Fukuda, M. Rab10 regulates tubular endosome formation through KIF13A and KIF13B motors. J Cell Sci 132, doi:10.1242/jcs.226977 (2019).

$6 \mathrm{Xu}, \mathrm{X} . \mathrm{H}$. et al. MARCKS regulates membrane targeting of Rab10 vesicles to promote axon development. Cell Res 24, 576-594, doi:10.1038/cr.2014.33 (2014).

7 Chen, Z. Y., leraci, A., Tanowitz, M. \& Lee, F. S. A novel endocytic recycling signal distinguishes biological responses of Trk neurotrophin receptors. Mol Biol Cell 16, 5761-5772, doi:10.1091/mbc.e05-07-0651 (2005).

8 Wang, H., Xu, J., Lazarovici, P., Quirion, R. \& Zheng, W. cAMP Response Element-Binding Protein (CREB): A Possible Signaling Molecule Link in the Pathophysiology of Schizophrenia. Front Mol Neurosci 11, 255, doi:10.3389/fnmol.2018.00255 (2018).

9 Esvald, E. E. et al. CREB Family Transcription Factors Are Major Mediators of BDNF Transcriptional Autoregulation in Cortical Neurons. J Neurosci 40, 1405-1426, doi:10.1523/JNEUROSCI.0367-19.2019 (2020).

Kwon, M., Fernandez, J. R., Zegarek, G. F., Lo, S. B. \& Firestein, B. L. BDNF-promoted increases in proximal dendrites occur via CREB-dependent transcriptional regulation of cypin. J Neurosci 31, 97359745, doi:10.1523/JNEUROSCI.6785-10.2011 (2011).

1 Cohen, M. S., Bas Orth, C., Kim, H. J., Jeon, N. L. \& Jaffrey, S. R. Neurotrophin-mediated dendrite-tonucleus signaling revealed by microfluidic compartmentalization of dendrites. Proc Natl Acad Sci U S A 108, 11246-11251, doi:10.1073/pnas.1012401108 (2011).

2 Riccio, A., Pierchala, B. A., Ciarallo, C. L. \& Ginty, D. D. An NGF-TrkA-mediated retrograde signal to transcription factor CREB in sympathetic neurons. Science 277, 1097-1100, doi:10.1126/science.277.5329.1097 (1997).

Lazo, O. M. et al. BDNF regulates Rab11-mediated recycling endosome dynamics to induce dendritic branching. J Neurosci 33, 6112-6122, doi:10.1523/JNEUROSCI.4630-12.2013 (2013).

4 Moya-Alvarado, G., Gonzalez, A., Stuardo, N. \& Bronfman, F. C. Brain-Derived Neurotrophic Factor (BDNF) Regulates Rab5-Positive Early Endosomes in Hippocampal Neurons to Induce Dendritic Branching. Front Cell Neurosci 12, 493, doi:10.3389/fncel.2018.00493 (2018).

5 Chua, C. E. L. \& Tang, B. L. Rab 10-a traffic controller in multiple cellular pathways and locations. J Cell Physiol 233, 6483-6494, doi:10.1002/jcp.26503 (2018).

6 Taylor, C. A., Yan, J., Howell, A. S., Dong, X. \& Shen, K. RAB-10 Regulates Dendritic Branching by Balancing Dendritic Transport. PLoS Genet 11, e1005695, doi:10.1371/journal.pgen.1005695 (2015). Waschbusch, D. et al. Structural Basis for Rab8a Recruitment of RILPL2 via LRRK2 Phosphorylation of Switch 2. Structure 28, 406-417 e406, doi:10.1016/j.str.2020.01.005 (2020).

Cockburn, J. J. B. et al. Insights into Kinesin-1 Activation from the Crystal Structure of KLC2 Bound to JIP3. Structure 26, 1486-1498 e1486, doi:10.1016/j.str.2018.07.011 (2018). 
bioRxiv preprint doi: https://doi.org/10.1101/2021.04.07.438771; this version posted April 7, 2021. The copyright holder for this preprint (which was not certified by peer review) is the author/funder, who has granted bioRxiv a license to display the preprint in perpetuity. It is made available under aCC-BY-ND 4.0 International license.

OM Lazo and G Schiavo, 2021 - pre-print version to be peer reviewed

39 Isabet, T. et al. The structural basis of Arf effector specificity: the crystal structure of ARF6 in a complex with JIP4. EMBO J 28, 2835-2845, doi:10.1038/emboj.2009.209 (2009).

40 Huang, S. H. et al. JIP3 mediates TrkB axonal anterograde transport and enhances BDNF signaling by directly bridging TrkB with kinesin-1. J Neurosci 31, 10602-10614, doi:10.1523/JNEUROSCI.043611.2011 (2011).

41 Sun, T. et al. JIP1 and JIP3 cooperate to mediate TrkB anterograde axonal transport by activating kinesin-1. Cell Mol Life Sci 74, 4027-4044, doi:10.1007/s00018-017-2568-z (2017).

42 Mir, R. et al. The Parkinson's disease VPS35[D620N] mutation enhances LRRK2-mediated Rab protein phosphorylation in mouse and human. Biochem J 475, 1861-1883, doi:10.1042/BCJ20180248 (2018).

43 Rohe, M., Hartl, D., Fjorback, A. N., Klose, J. \& Willnow, T. E. SORLA-mediated trafficking of TrkB enhances the response of neurons to BDNF. PLoS One 8, e72164, doi:10.1371/journal.pone.0072164 (2013).

44 Kluss, J. H., Mamais, A. \& Cookson, M. R. LRRK2 links genetic and sporadic Parkinson's disease. Biochem Soc Trans 47, 651-661, doi:10.1042/BST20180462 (2019).

45 Tolosa, E., Vila, M., Klein, C. \& Rascol, O. LRRK2 in Parkinson disease: challenges of clinical trials. Nat Rev Neurol 16, 97-107, doi:10.1038/s41582-019-0301-2 (2020).

46 Qin, Q. et al. Effects of LRRK2 Inhibitors on Nigrostriatal Dopaminergic Neurotransmission. CNS Neurosci Ther 23, 162-173, doi:10.1111/cns.12660 (2017).

47 Rocha, E. M. et al. LRRK2 inhibition prevents endolysosomal deficits seen in human Parkinson's disease. Neurobiol Dis 134, 104626, doi:10.1016/j.nbd.2019.104626 (2020).

48 Sano, H. et al. Rab10, a target of the AS160 Rab GAP, is required for insulin-stimulated translocation of GLUT4 to the adipocyte plasma membrane. Cell Metab 5, 293-303, doi:10.1016/j.cmet.2007.03.001 (2007).

49 Funk, N. et al. The Parkinson's disease-linked Leucine-rich repeat kinase 2 (LRRK2) is required for insulin-stimulated translocation of GLUT4. Sci Rep 9, 4515, doi:10.1038/s41598-019-40808-y (2019).

50 Andreska, T., Luningschror, P. \& Sendtner, M. Regulation of TrkB cell surface expression-a mechanism for modulation of neuronal responsiveness to brain-derived neurotrophic factor. Cell Tissue Res 382, 5-14, doi:10.1007/s00441-020-03224-7 (2020).

51 Liu, O. \& Grant, B. D. Basolateral Endocytic Recycling Requires RAB-10 and AMPH-1 Mediated Recruitment of RAB-5 GAP TBC-2 to Endosomes. PLoS Genet 11, e1005514, doi:10.1371/journal.pgen.1005514 (2015).

52 Shi, A. \& Grant, B. D. Interactions between Rab and Arf GTPases regulate endosomal phosphatidylinositol-4,5-bisphosphate during endocytic recycling. Small GTPases 4, 106-109, doi:10.4161/sgtp.23477 (2013).

53 Matsuda, N. et al. Differential activity-dependent secretion of brain-derived neurotrophic factor from axon and dendrite. J Neurosci 29, 14185-14198, doi:10.1523/JNEUROSCI.1863-09.2009 (2009).

$54 \mathrm{Fu}, \mathrm{X}$. et al. Retrolinkin cooperates with endophilin A1 to mediate BDNF-TrkB early endocytic trafficking and signaling from early endosomes. Mol Biol Cell 22, 3684-3698, doi:10.1091/mbc.E11-040308 (2011).

55 Matta, S. et al. LRRK2 controls an EndoA phosphorylation cycle in synaptic endocytosis. Neuron 75, 1008-1021, doi:10.1016/j.neuron.2012.08.022 (2012).

56 Van Acker, Z. P., Bretou, M. \& Annaert, W. Endo-lysosomal dysregulations and late-onset Alzheimer's disease: impact of genetic risk factors. Mol Neurodegener 14, 20, doi:10.1186/s13024-019-0323-7 (2019).

57 Xu, W., Fang, F., Ding, J. \& Wu, C. Dysregulation of Rab5-mediated endocytic pathways in Alzheimer's disease. Traffic 19, 253-262, doi:10.1111/tra.12547 (2018).

58 Kaech, S. \& Banker, G. Culturing hippocampal neurons. Nat Protoc 1, 2406-2415, doi:10.1038/nprot.2006.356 (2006). 
bioRxiv preprint doi: https://doi.org/10.1101/2021.04.07.438771; this version posted April 7, 2021. The copyright holder for this preprint (which

was not certified by peer review) is the author/funder, who has granted bioRxiv a license to display the preprint in perpetuity. It is made available under aCC-BY-ND 4.0 International license.

OM Lazo and G Schiavo, 2021 - pre-print version to be peer reviewed

59 Sannerud, R. et al. ADP ribosylation factor 6 (ARF6) controls amyloid precursor protein (APP) processing by mediating the endosomal sorting of BACE1. Proc Natl Acad Sci U S A 108, E559-568, doi:10.1073/pnas.1100745108 (2011).

60 Restani, L. et al. Botulinum neurotoxins $A$ and $E$ undergo retrograde axonal transport in primary motor neurons. PLoS Pathog 8, e1003087, doi:10.1371/journal.ppat.1003087 (2012).

61 Huang, B. et al. The Anaplasma phagocytophilum-occupied vacuole selectively recruits Rab-GTPases that are predominantly associated with recycling endosomes. Cell Microbiol 12, 1292-1307, doi:10.1111/j.1462-5822.2010.01468.x (2010).

62 Culley, S., Tosheva, K. L., Matos Pereira, P. \& Henriques, R. SRRF: Universal live-cell super-resolution microscopy. Int J Biochem Cell Biol 101, 74-79, doi:10.1016/j.biocel.2018.05.014 (2018).

63 Culley, S. et al. Quantitative mapping and minimization of super-resolution optical imaging artifacts. Nat Methods 15, 263-266, doi:10.1038/nmeth.4605 (2018).

64 Neumann, S., Chassefeyre, R., Campbell, G. E. \& Encalada, S. E. KymoAnalyzer: a software tool for the quantitative analysis of intracellular transport in neurons. Traffic 18, 71-88, doi:10.1111/tra.12456 (2017). 
bioRxiv preprint doi: https://doi.org/10.1101/2021.04.07.438771; this version posted April 7, 2021. The copyright holder for this preprint (which was not certified by peer review) is the author/funder, who has granted bioRxiv a license to display the preprint in perpetuity. It is made available under aCC-BY-ND 4.0 International license.

OM Lazo and G Schiavo, 2021 - pre-print version to be peer reviewed

\section{Figures}

\section{Figure 1. Rab10 is required for retrograde TrkB trafficking and signalling.}

(a) Schematic of two-compartment microfluidic chambers highlighting compartimentalisation of somata (left) and axon terminals (right). Micro-flow from somatic to axonal compartments provides fluidic isolation of the axonal compartment. (b) Representative images from the cell bodies of neurons incubated for 2.5 hours with anti-TrkB in the axonal compartment, with $(+)$ or without (-) BDNF. Pink arrowheads indicate examples of retrogradely transported TrkB-positive organelles. Scale bar: $10 \mu \mathrm{m}$. (c) Neurons treated with an inducible shRNA targeting Rab10 were compared to control neurons. Immunofluorescence revealed similar neuronal density (see ßIII-tubulin in orange and nuclear staining in green, top panel), but a decrease in both, expression of Rab10 (gray, middle panel) and retrograde accumulation of TrkB after 2.5 hours (colour intensity scale, bottom panel). Scale bar: $50 \mu \mathrm{m}$ (d) Quantification of retrograde TrkB accumulation in three independent experiments show statistically significant differences (unpaired t-Student test, $\mathrm{t}(140), \mathrm{p}<$ 0.0001 ). (e) Analysis of the correlation between expression level of Rab10 and retrograde TrkB accumulation in the whole population of control and Rab10-knockdown neurons show a significant linear correlation (Goodness of fit $R^{2}=0.61$; Pearson $r$, $X Y$ pairs= 131, $p<0.0001$ ). (f) Axonal stimulation with BDNF for 2.5 hours leads to robust appearance of phosphorylated CREB in the nucleus of control neurons (left panel). This was restricted in neurons depleted of Rab10 (middle panel), which was rescued by the coexpression of a shRNA-resistant mutant Rab10 (right panel). Immunofluorescence for Rab10 is shown in gray, with the nuclei indicated with a pink mask, and nuclear phosphorylated CREB is shown in a colour intensity scale. Scale bar: $50 \mu \mathrm{m}$. (g) Quantification from three independent experiments showing the statistically significant effect of manipulating Rab10 expression on the levels of phosphorylated CREB in the nucleus (oneway ANOVA, $F(2,280), p<0.0001 ; p$ values for the Bonferroni multiple comparison tests, $t(280)$, are indicated in the plot).

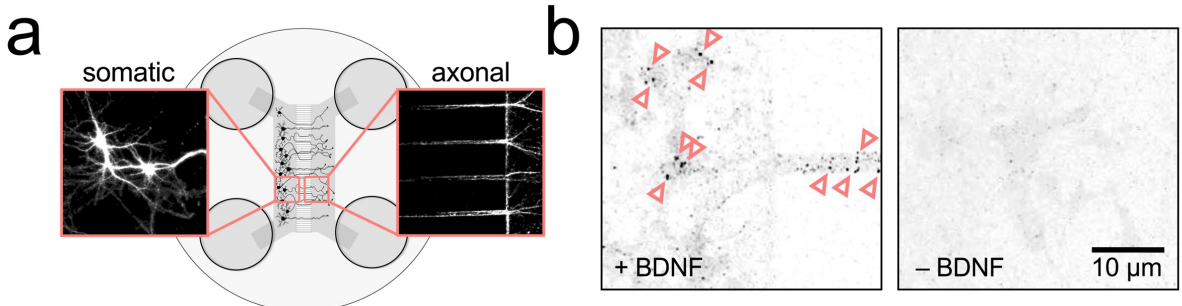

C

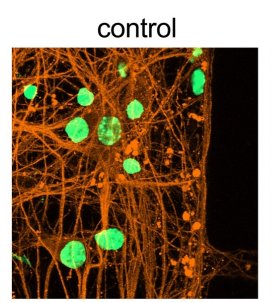

shRNA Rab10

d
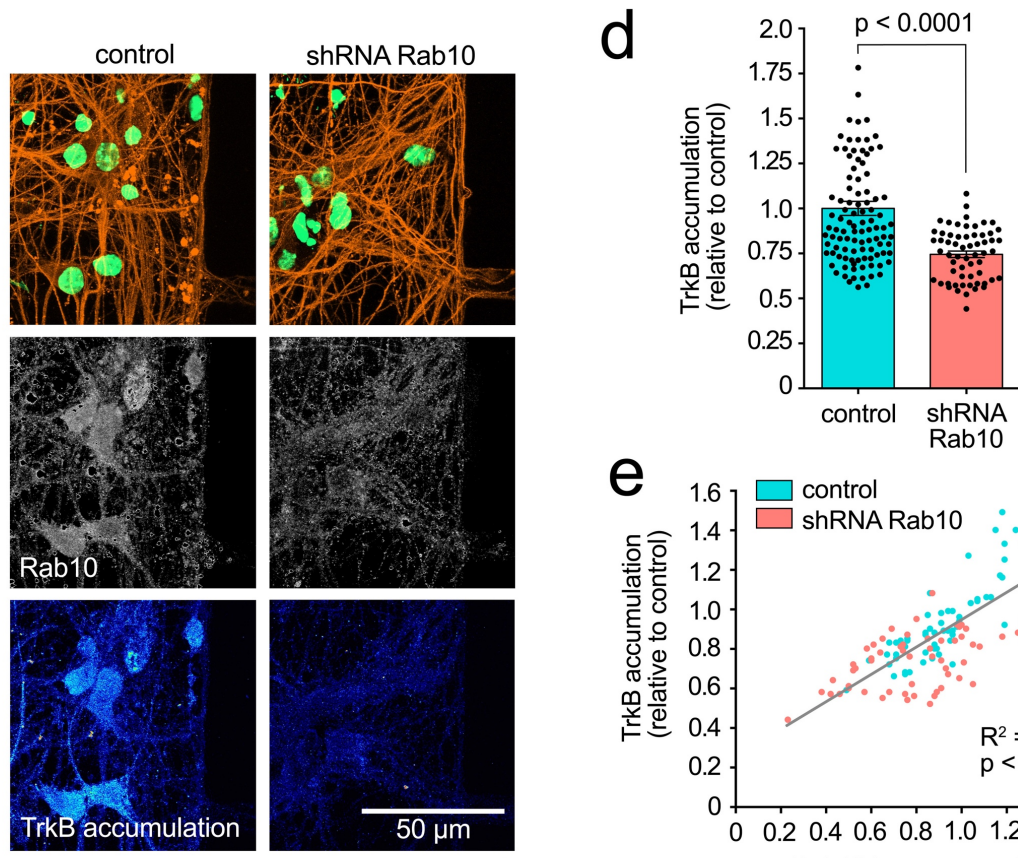

DAPI ßIII Tubulin $\begin{aligned} & \text { E } \\ & 0\end{aligned}$
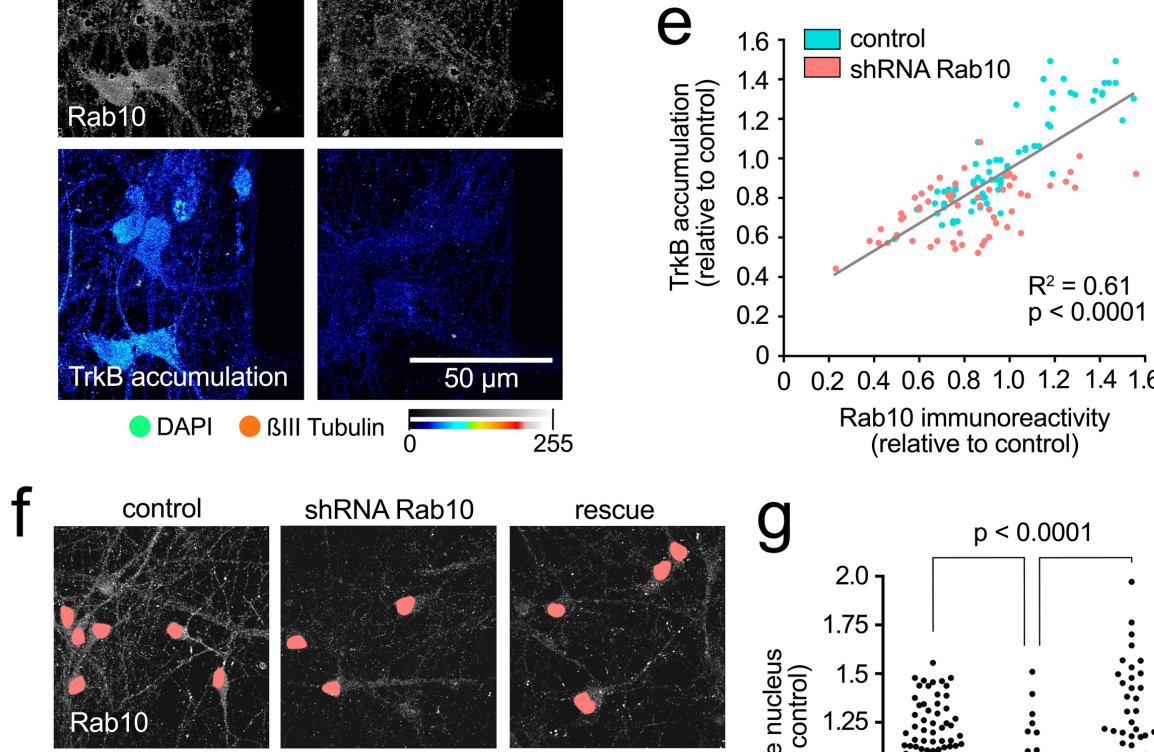

g
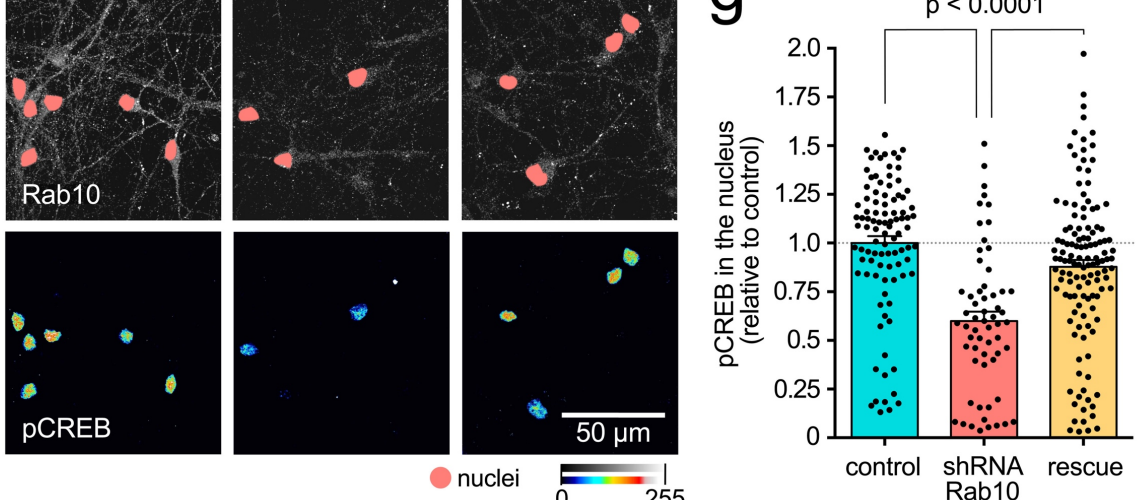

(relative to control)

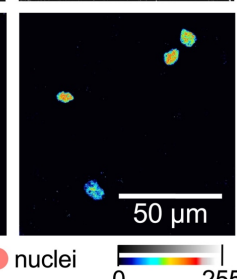


bioRxiv preprint doi: https://doi.org/10.1101/2021.04.07.438771; this version posted April 7, 2021. The copyright holder for this preprint (which was not certified by peer review) is the author/funder, who has granted bioRxiv a license to display the preprint in perpetuity. It is made available under aCC-BY-ND 4.0 International license.

OM Lazo and G Schiavo, 2021 - pre-print version to be peer reviewed

Figure 2. Internalised TrkB transiently co-localises with Rab10 in axons.
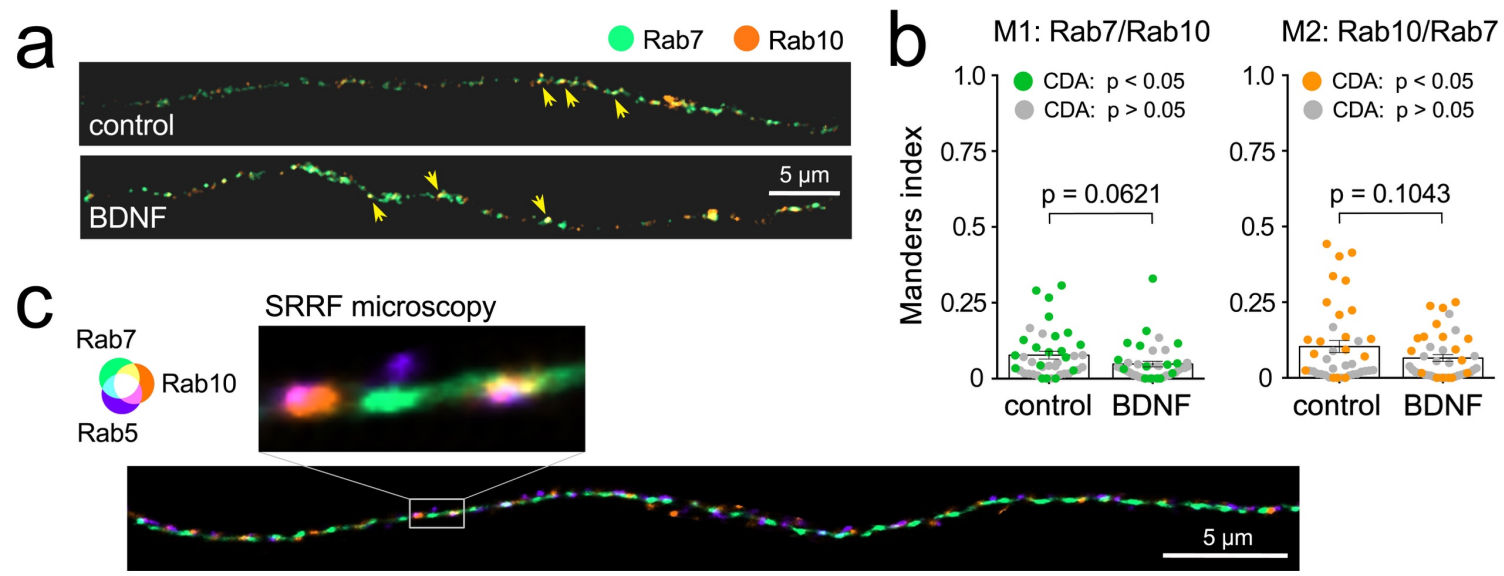

O
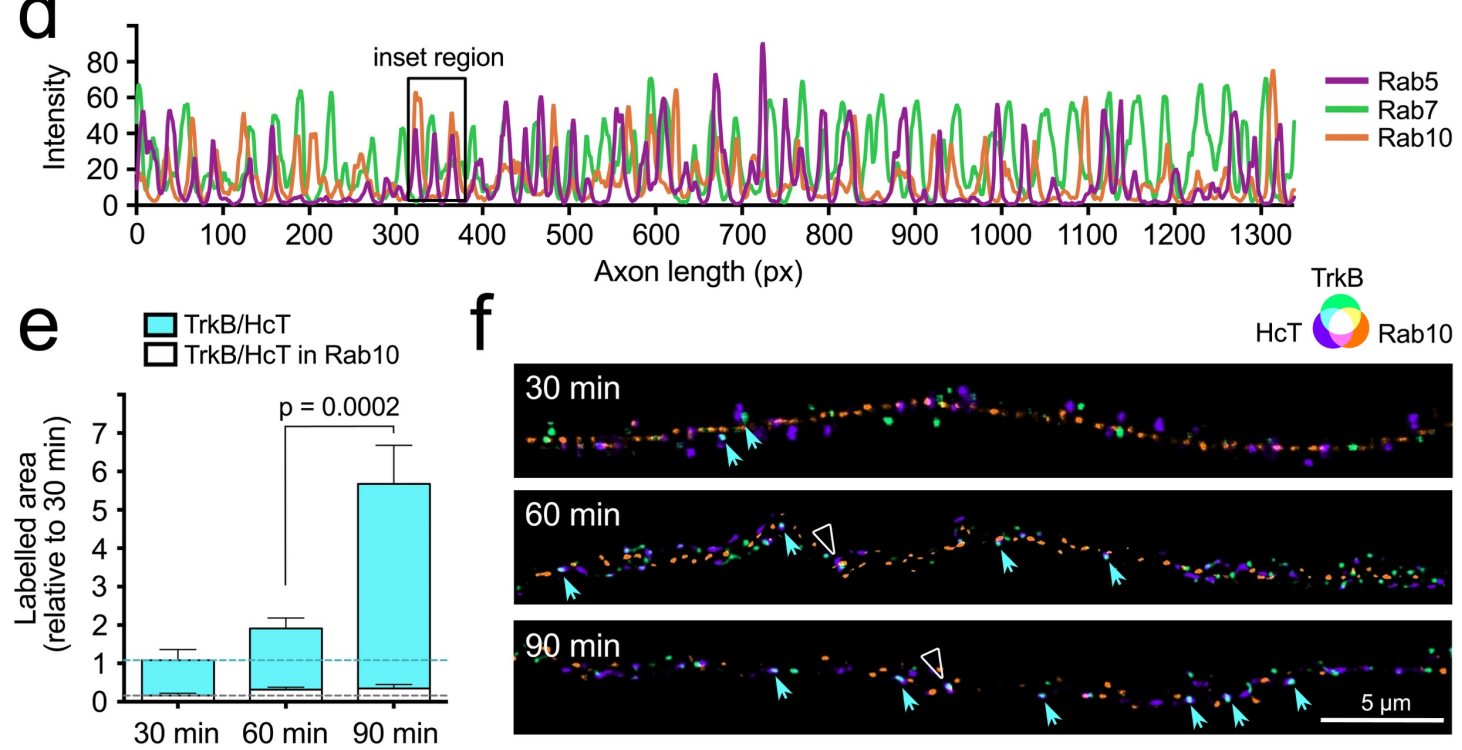

(a) The distribution of endogenous Rab10 (orange) and Rab7 (green) was monitored using confocal microscopy in axons of neurons with or without BDNF treatment for $30 \mathrm{~min}$. Points where both markers overlap are indicated with yellow arrowheads. Scale bar $=5$ $\mu \mathrm{m}$ (b) Co-localisation was analysed using confined-displacement algorithm (CDA), and Manders coefficients were compared for control versus BDNF-treated axons (Welch's corrected Unpaired t-Student; $M 1$ : $t(72.32), p$ value $=0.0621 ; M 2: t(62.33), p$ value = 0.1043). Data points showing significant co-localisation compared to random scenarios are indicated in coloured dots. No significant differences were found between starved and BDNF-stimulated neurons. (c) Representative super-resolution radial fluctuations (SRRF) microscopy of an axon stained for endogenous Rab5 (purple), Rab7 (green) and Rab10 (orange). The inset at 6x higher magnification shows examples of partial co-localisation of Rab10 with Rab5 and Rab7. Scale bar $=5 \mu \mathrm{m}$. (d) Intensity along the same axonal segment shown in (c) was plotted to observe the correlation between the three markers. The region of the inset is indicated. Several examples of partial coincidence between Rab10 and Rab5 are observed. Overlap between Rab10 and Rab7 peaks is less frequent, confirming the data in (a) and (b). (e) Labelled $\mathrm{H}_{\mathrm{C}} \mathrm{T}$ and anti-TrkB were co-internalised in the presence of BDNF for 30, 60 and 90 min, and then their level of overlap with endogenous Rab10 in axons was evaluated using confocal microscopy. Relative area positive for $\mathrm{H}_{\mathrm{C}} \mathrm{T}$ and $\mathrm{TrkB}_{\mathrm{B}}$ is shown in cyan (normalised to $30 \mathrm{~min}$ ) and the fraction of the normalised area that was triple positive for $\mathrm{H}_{\mathrm{C}} \mathrm{T}$, TrkB and Rab10 is plotted in white. While the double TrkB/ $\mathrm{H}_{C} T$-positive area significantly increased by 90 min (one-way ANOVA, $F(2,72), p$ value $<0.0001$; Bonferroni multiple comparison test $p$ value is shown in the plot), the triple TrkB/ $H_{C} T / R a b 10$ surface remained low and fairly constant at all the time points (one-way ANOVA, $F(2,72)$, $p$ value $=0.2730$; Bonferroni multiple comparisons test for 60 versus 90 min, $t(72), p$ value $>0.9999$ ). (f) Representative SRRF microscopy from the same three time points. Double positive puncta for $T r k B$ (green) and $H_{C} T$ (purple) is indicated with cyan arrowheads. Triple positive puncta of TrkB/ $H_{C} T$ (cyan) and Rab10 (orange) are indicated with white empty triangles. Scale bar $=5 \mu \mathrm{m}$. 
bioRxiv preprint doi: https://doi.org/10.1101/2021.04.07.438771; this version posted April 7, 2021. The copyright holder for this preprint (which was not certified by peer review) is the author/funder, who has granted bioRxiv a license to display the preprint in perpetuity. It is made available under aCC-BY-ND 4.0 International license.

OM Lazo and G Schiavo, 2021 - pre-print version to be peer reviewed

Figure 3. Over-expressed Rab10 is co-transported with TrkB and p75 receptors in the axon.

a

b

Rab10 WT

+ TrkB-Flag
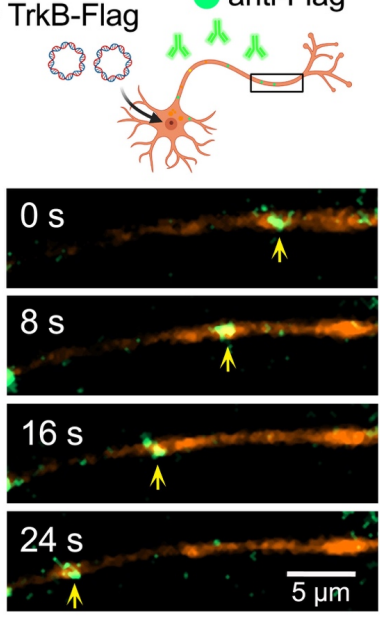

e

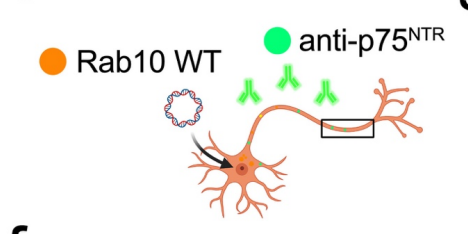

f
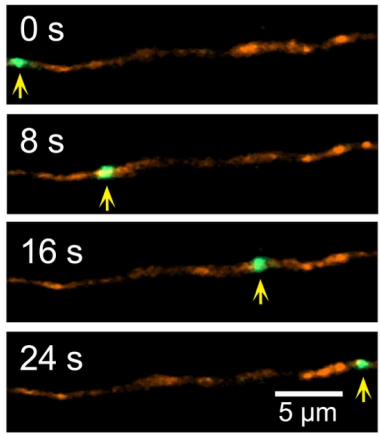

C
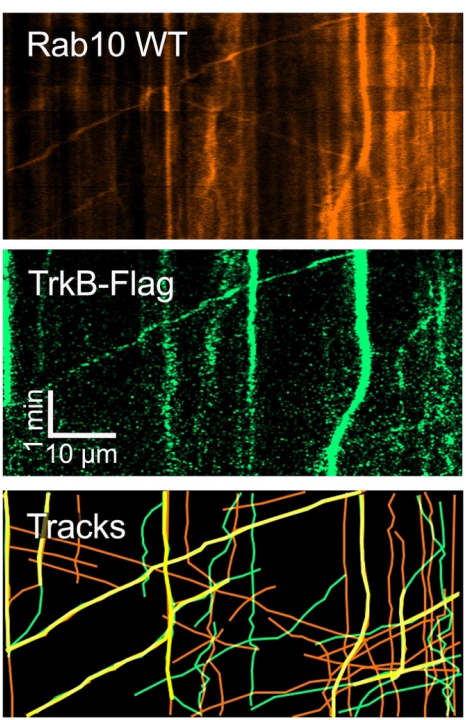

d

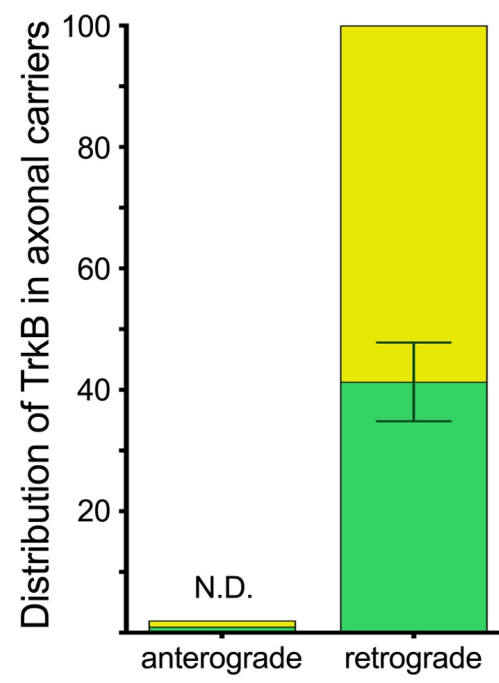

h
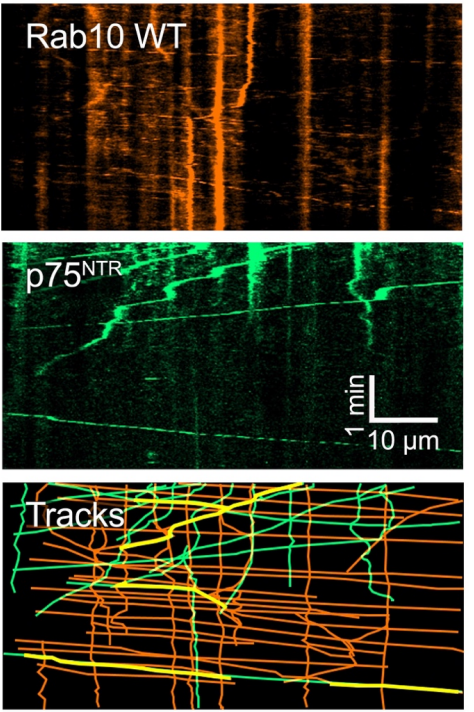

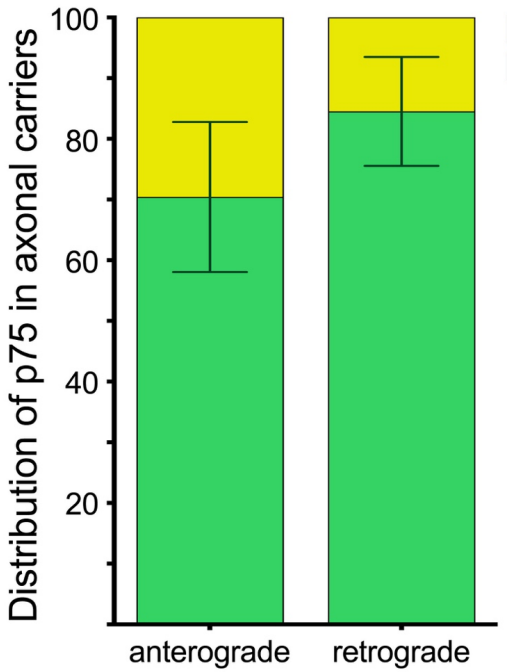

TrkB/Rab10 TrkB only

p75 NTR/Rab10 p $75^{\text {NTR }}$ only

(a) Hippocampal neurons were co-transfected with Rab10-EGFP and TrkB-Flag plasmids. Fluorescently-labelled anti-Flag antibodies were internalised in the presence of BDNF and their axonal dynamics monitored by live-cell microscopy. (b) Representative images of the axon of a double transfected neuron, where a double-positive organelle for Rab10-EGFP (orange) and anti-Flag (green) is indicated with yellow arrowheads. Scale bar $=5 \mu \mathrm{m}$. (c) Representative kymograph of the axon of a double transfected neuron during 5 minutes of imaging showing Rab10 and TrkB-Flag channels, and traced tracks with double-positive tracks in yellow showing transport predominantly in the retrograde direction (right to left). Scale bar $=10 \mu \mathrm{m}$. (d) Quantification of five experiments showing the proportion of TrkB mobile organelles that were positive for Rab10. No anterograde TrkB organelles were found; therefore, presence of Rab10 could not be determined (N.D.). (e) Same experiment was performed by transfecting Rab10 and visualising it together with fluorescently-labelled anti-p75NTR antibodies. (f) Representative sequence of images from a live axon shows a double-positive organelle for Rab10 (orange) and p75 NTR (green) moving anterogradely. Scale bar $=5 \mu \mathrm{m}$. (g) Representative kymograph showing Rab10 and p75 NTR channels, and traced tracks in yellow showing transport in both anterograde (left to right) and retrograde directions. Scale bar $=10 \mu \mathrm{m}$. (h) Quantification of five experiments showing the proportion of p $75^{\text {NTR }}$ mobile organelles that were positive for Rab10 in the anterograde and retrograde direction. 
bioRxiv preprint doi: https://doi.org/10.1101/2021.04.07.438771; this version posted April 7, 2021. The copyright holder for this preprint (which was not certified by peer review) is the author/funder, who has granted bioRxiv a license to display the preprint in perpetuity. It is made available under aCC-BY-ND 4.0 International license.

OM Lazo and G Schiavo, 2021 - pre-print version to be peer reviewed

Figure 4. BDNF regulates the directionality of Rab10 organelles.

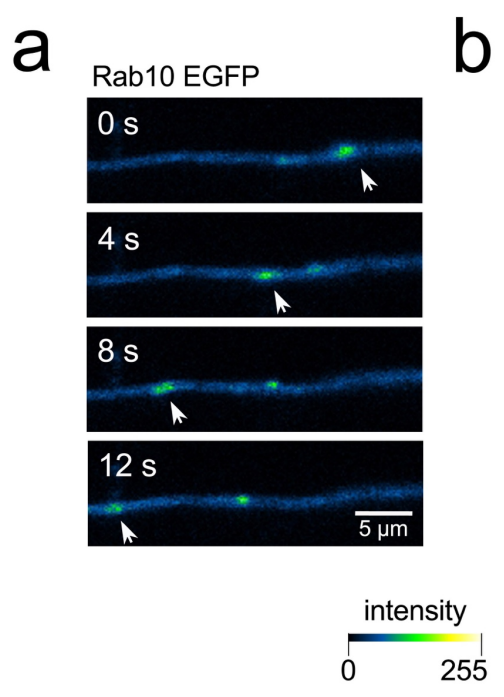

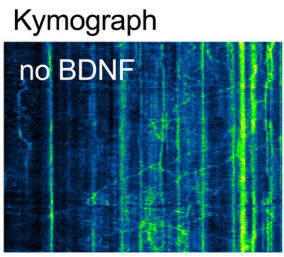
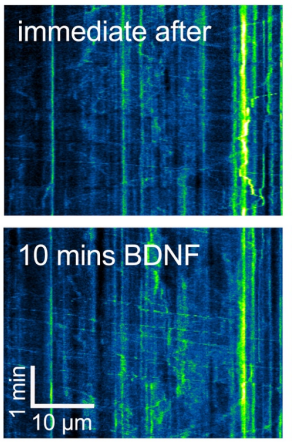
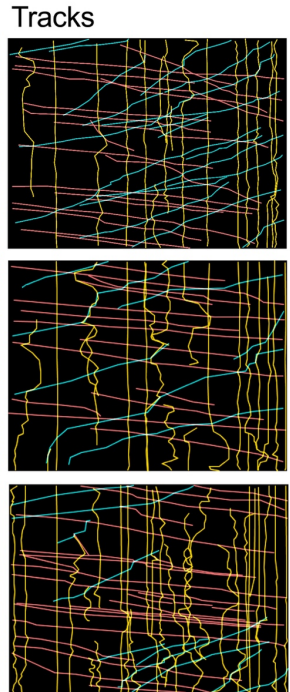

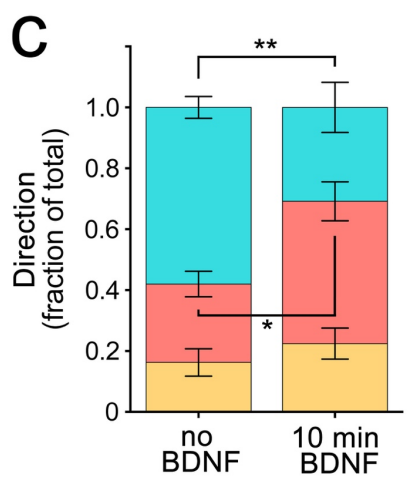

Retrograde

Anterograde

Stationary or bidirectional

Hippocampal neurons were transfected with Rab10-EGFP and depleted of BDNF for 60 mins. (a) Representative axon of a live neuron showing retrograde (right to left) transport of a Rab10-positive organelle (white arrowheads). Scale bar $=5 \mu \mathrm{m}$. (b) In the panels on the left, representative kymographs (colour-coded as in a) are presented from the same axon after BDNF depletion (top), immediately after the addition of $50 \mathrm{ng} / \mathrm{mL}$ of BDNF (middle) and 10 minutes after (bottom). In the panels on the right side, the tracks have been traced and categorised as retrograde (cyan), anterograde (pink) or stationary/bidirectional (yellow). Scale bar $=10 \mu \mathrm{m}$. (c) The frequencies of tracks from each of the three categories have been quantified and plotted comparing no BDNF and 10 min post-addition of $50 \mathrm{ng} / \mathrm{mL}$ BDNF. $\mathrm{N}=14$ axonal segments from 10 independent experiments. Unpaired t-Student, $\mathrm{t}(14)$, showed a significant increase in anterograde carriers ( $p$ value $=0.0150,{ }^{*}$ ) at the expense of retrograde carriers ( $p$ value $=0.003,{ }^{* *}$ ). Stationary and bidirectional carriers did not show any significant change ( $p$ value $=0.4278)$. 
bioRxiv preprint doi: https://doi.org/10.1101/2021.04.07.438771; this version posted April 7, 2021. The copyright holder for this preprint (which was not certified by peer review) is the author/funder, who has granted bioRxiv a license to display the preprint in perpetuity. It is made available under aCC-BY-ND 4.0 International license.

OM Lazo and G Schiavo, 2021 - pre-print version to be peer reviewed

Figure 5. Rab10 regulates sorting of TrkB out of early endosomes.

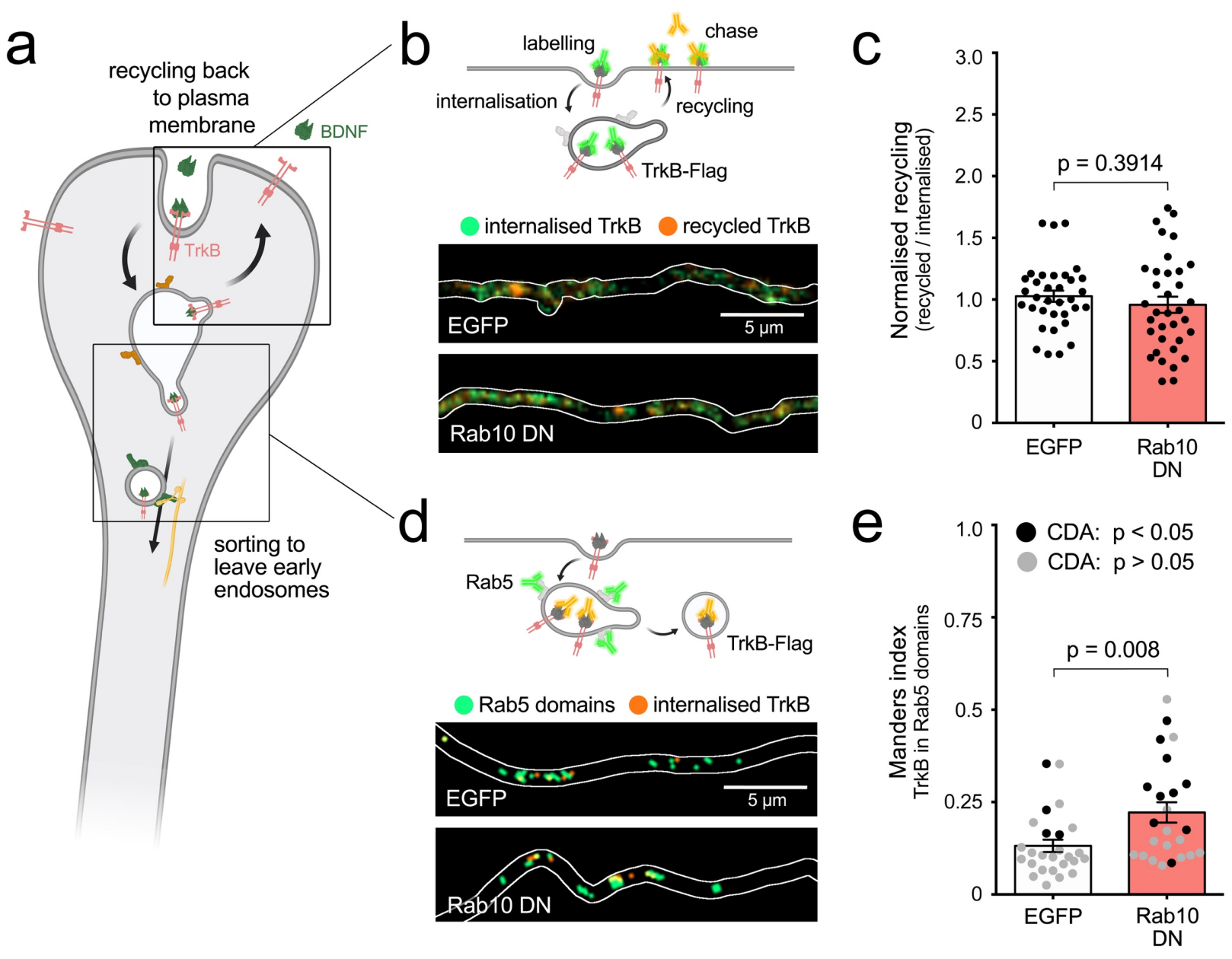

(a) Main hypotheses about the role of Rab10 regulating the sorting of TrkB to signalling endosomes include recycling back to the plasma membrane or sorting of TrkB receptors out of early endosomes to retrograde carriers. (b) Top, diagram of the experiment showing TrkB-flag receptors on the axonal surface bound to anti-Flag antibodies (green). After internalisation, the remaining anti-Flag is removed from the surface and the labelled receptor that recycled to the plasma membrane is chased with a secondary antibody (orange). Bottom, representative examples of internalised TrkB (green) and recycled TrkB (orange) in axons from neurons transfected with EGFP or a Rab10 DN mutant. (c) Normalised recycling shows no difference between EGFP and Rab10 DN transfected neurons. Unpaired t-Student, $\mathrm{t}(60.40)$, $\mathrm{p}$ value $=0.3914$. (d) Top, diagram of the internalisation of TrkB-flag labelled with anti-Flag antibodies (orange) to Rab5-positive early endosomes (green). Bottom, representative thresholded microscopy images from the axon of neurons transfected with EGFP or Rab10 DN mutant. While the amount of orange puncta are similar in both conditions, yellow areas showing co-localisation of internalised TrkB and Rab5 are increased upon Rab10 DN expression. (e) Quantification of co-localisation between internalised TrkB-Flag and endogenous Rab5 is significantly higher in neurons expressing Rab10 DN compared to EGFP. Unpaired tStudent, $t(38.22), p$ value $=0.008$. Significant co-localisation according to CDA ( $p$ value $<0.05$ compared to randomised signal) is shown with black circles, while inconclusive co-localisation ( $p$ value $>0.05$ ) is shown in grey. Scale bars $=5 \mu \mathrm{m}$. 
bioRxiv preprint doi: https://doi.org/10.1101/2021.04.07.438771; this version posted April 7, 2021. The copyright holder for this preprint (which was not certified by peer review) is the author/funder, who has granted bioRxiv a license to display the preprint in perpetuity. It is made available under aCC-BY-ND 4.0 International license.

OM Lazo and G Schiavo, 2021 - pre-print version to be peer reviewed

Figure 6. Model: Role of Rab10 in the sorting of TrkB to retrograde axonal transport.

At steady state, low concentrations of BDNF (grey side of the terminal) induce basal levels of TrkB internalisation. Rab10 supply (blue arrows) is in equilibrium and it mediates baseline level of TrkB retrograde transport (pink arrows). Upon increase of BDNF concentration (green side of the axon terminal), TrkB endocytosis as well as the proportion of Rab10 organelles moving towards the axon terminal are increased. Increased amounts of Rab10 result in further facilitation of the sorting of TrkB out of the early endosome and an augmented flux of retrograde signalling carriers.

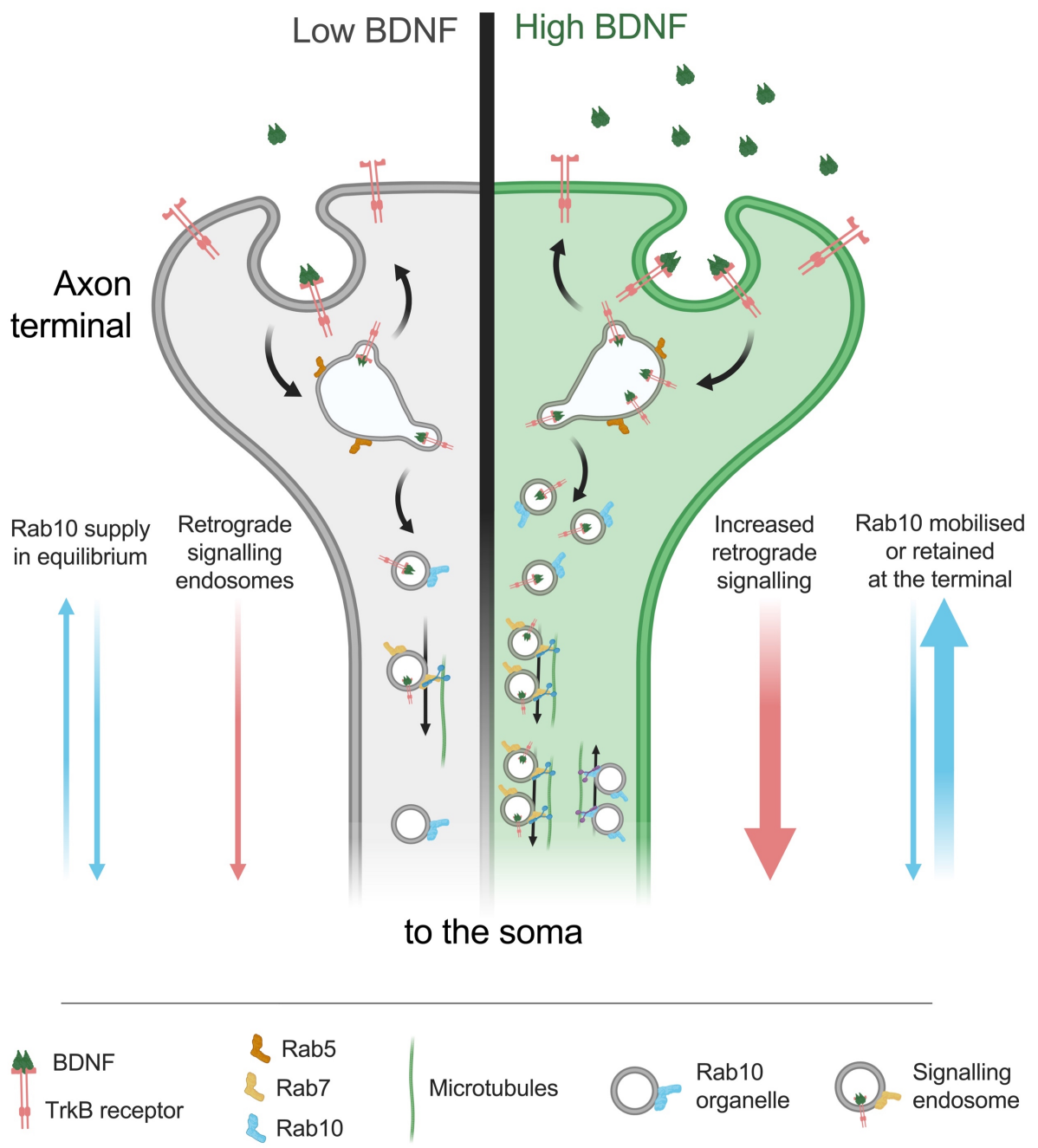


bioRxiv preprint doi: https://doi.org/10.1101/2021.04.07.438771; this version posted April 7, 2021. The copyright holder for this preprint (which was not certified by peer review) is the author/funder, who has granted bioRxiv a license to display the preprint in perpetuity. It is made available under aCC-BY-ND 4.0 International license.

OM Lazo and G Schiavo, 2021 - pre-print version to be peer reviewed

\section{Supplementary tables}

Table S1 - Resources

\begin{tabular}{|c|c|c|c|c|c|}
\hline \multicolumn{6}{|l|}{ Primary antibodies } \\
\hline antigen & host species & manufacturer & cat number & RRID & concentration \\
\hline Rab10 & goat & Santa Cruz Biotechnologies & sc-6564 & AB_2237844 & IF: $1: 50$ \\
\hline Rab10 & mouse & Abcam & ab104859 & AB_10711207 & IF: $1: 200$ \\
\hline Rab10 & rabbit & Cell Signalling & 8127 & $A B \_10828219$ & IF: $1: 200$ \\
\hline TrkB & rabbit & Merck (Millipore) & AB9872 & $A B \_11214317$ & IE: 1:50 \\
\hline Tubulin ßIII & chicken & Synaptic Systems & 302306 & AB__2620048 & IF: $1: 300$ \\
\hline phospho CREB & rabbit & Abcam & ab32096 & AB_731734 & IF: $1: 250$ \\
\hline Rab7 & mouse & Abcam & ab50533 & $A B \_882241$ & IF: $1: 200$ \\
\hline Rab5 & rabbit & Abcam & ab13253 & AB_299796 & IF: $1: 200$ \\
\hline Flag (M1) & mouse & Sigma & F3040 & $A B \_439712$ & IE: 1:100 \\
\hline p75NTR & rabbit & Cancer Research UK & CRD5410 & AB_2864325 & IE: 1:500 \\
\hline \multicolumn{6}{|l|}{ Lentiviral Vectors } \\
\hline name & & manufacturer & cat number & & \\
\hline TET ON Advance & & akara Bio (Clontech) & 630930 & & \\
\hline pLVX shRab10 & & Schiavo Lab & - & & \\
\hline pLVX Rab10 myc & & Schiavo Lab & - & & \\
\hline \multicolumn{6}{|l|}{ Plasmids } \\
\hline product & & manufacturer & Addgene & RRID & reference \\
\hline pEGFP-C1 & & Clontech & \multicolumn{3}{|c|}{ (discontinued) } \\
\hline Rab10 WT EGFP & & Marci Scidmore lab & 49472 & Addgene_49472 & Huang 2010 Cell Microbiol \\
\hline Rab10 T23N EGFP & & Marci Scidmore lab & 49545 & Addgene_49545 & Huang 2010 Cell Microbiol \\
\hline TrkB-FLAG & & Francis Lee lab & - & - & Chen 2005 Mol Biol Cell \\
\hline
\end{tabular}

Table S1: Primary antibodies, lentiviral vectors and plasmids used in this study. RRID: Research Resource Identifier.

IF: immunofluorescence. IE: immuno-endocytosis.

Table S2 - Statistical summary

\begin{tabular}{|c|c|c|c|c|c|c|}
\hline \multicolumn{2}{|c|}{ Figure } & Variable & Test & Groups & Degrees of freedom & p value \\
\hline \multirow{5}{*}{1} & D & TrkB accumulation & Unpaired t-Student & control : shRNA Rab10 & $t(140)$ & $<0.0001$ \\
\hline & E & TrkB accumulation and Rab10 expression & Pearson $r$ & control : shRNA Rab10 & $\mathrm{XY}$ pairs $=131$ & $<0.0001$ \\
\hline & \multirow{3}{*}{ G } & \multirow{3}{*}{ pCREB abundance } & one-way ANOVA & control, shRNA Rab10 and rescue & $F(2,280)$ & $<0.0001$ \\
\hline & & & Multiple comparisons & control : shRNA Rab10 & $t(280)$ & $<0.0001$ \\
\hline & & & Multiple comparisons & control : rescue & $\mathrm{t}(280)$ & 0.0336 \\
\hline \multirow{8}{*}{2} & \multirow{2}{*}{ B } & \multirow{2}{*}{ Co-localisation Rab10 and Rab7 } & Unpaired t-Student & M1 control : BDNF & $t(72.32)$ & 0.0621 \\
\hline & & & Unpaired t-Student & M2 control : BDNF & $t(62.33)$ & 0.1043 \\
\hline & \multirow{6}{*}{$\mathrm{E}$} & \multirow{3}{*}{ Area of overlay HcT and TrkB (retrograde TrkB) } & one-way ANOVA & 30,60 and 90 mins & $F(2,72)$ & $<0.0001$ \\
\hline & & & Multiple comparisons & $30: 60$ mins & $t(72)$ & $>0.9999$ \\
\hline & & & Multiple comparisons & $60: 90$ mins & $t(72)$ & 0.0002 \\
\hline & & \multirow{3}{*}{ Area of overlay retrograde TrkB and Rab10 } & one-way ANOVA & 30,60 and 90 mins & $F(2,72)$ & 0.2730 \\
\hline & & & Multiple comparisons & $30: 60$ mins & $t(72)$ & 0.5717 \\
\hline & & & Multiple comparisons & $60: 90$ mins & $t(72)$ & $>0.9999$ \\
\hline \multirow{3}{*}{4} & \multirow{3}{*}{ C } & \multirow{3}{*}{ Direction of Rab10 organelles } & Unpaired t-Student & Anterograde pre : post BDNF & $t(14)$ & 0.0150 \\
\hline & & & Unpaired t-Student & Retrograde pre : post BDNF & $t(14)$ & 0.0030 \\
\hline & & & Unpaired t-Student & Non-mobile pre : post BDNF & $t(14)$ & 0.4278 \\
\hline \multirow{2}{*}{5} & C & Recycling of TrkB & Unpaired t-Student & EGFP : Rab10 DN & $t(60.40)$ & 0.3914 \\
\hline & E & Co-localisation TrkB and Rab5 & Unpaired t-Student & EGFP : Rab10 DN & $\mathrm{t}(38.22)$ & 0.0080 \\
\hline
\end{tabular}

Table S2: Summary of the statistical tests and their results for the data in the figures. 